OPEN ACCESS

Edited by:

David John Oliver,

University of Kent, United Kingdom

Reviewed by:

Gian Domenico Borasio

Centre Hospitalier Universitaire

Vaudois (CHUV), Switzerland

Valentina Pasian,

Azienda Sanitaria Locale 'Città di

Torino', Italy

*Correspondence:

Andreas Hermann

andreas.hermann@

uniklinikum-dresden.de

tThese authors have contributed equally to this work

Specialty section:

This article was submitted to Neuromuscular Diseases,

a section of the journal

Frontiers in Neurology

Received: 29 March 2018 Accepted: 06 July 2018

Published: 27 July 2018

Citation:

Linse $K$, Aust $E$, Joos $M$ and Hermann A (2018) Communication

Matters - Pitfalls and Promise of Hightech Communication Devices in Palliative Care of Severely Physically Disabled Patients With Amyotrophic Lateral Sclerosis. Front. Neurol. 9:603. doi: 10.3389/fneur.2018.00603

\section{Communication Matters - Pitfalls and Promise of Hightech Communication Devices in Palliative Care of Severely Physically Disabled Patients With Amyotrophic Lateral Sclerosis}

\author{
Katharina Linse ${ }^{1,2 \dagger}$, Elisa Aust ${ }^{1 \dagger}$, Markus Joos ${ }^{3}$ and Andreas Hermann ${ }^{1,2 *}$ \\ ${ }^{1}$ Department of Neurology, Technische Universität Dresden, Dresden, Germany, ${ }^{2}$ German Center for Neurodegenerative \\ Diseases (DZNE) Dresden, Dresden, Germany, ${ }^{3}$ Interactive Minds Dresden GmbH, Dresden, Germany
}

Amyotrophic lateral sclerosis (ALS) is the most common motor neuron disease, leading to progressive paralysis, dysarthria, dysphagia, and respiratory disabilities. Therapy is mostly focused on palliative interventions. During the course of the disease, verbal as well as nonverbal communicative abilities become more and more impaired. In this light, communication has been argued to be "the essence of human life" and crucial for patients' quality of life. High-tech augmentative and alternative communication (HT-AAC) technologies such as eyetracking based computer devices and brain-computer-interfaces provide the possibility to maintain caregiver-independent communication and environmental control even in the advanced disease state of ALS. Thus, they enable patients to preserve social participation and to independently communicate end-of-life-decisions. In accordance with these functions of HT-AAC, their use is reported to strengthen self-determination, increase patients' quality of life and reduce caregiver burden. Therefore, HT-AAC should be considered as standard of (palliative) care for people with ALS. On the other hand, the supply with individually tailored HT-AAC technologies is limited by external and patient-inherent variables. This review aims to provide an overview of the possibilities and limitations of HT-AAC technologies and discuss their role in the palliative care for patients with ALS.

Keywords: amyotrophic lateral sclerosis, augmentative and alternative communication technologies, eyetracking, brain-computer-interfaces, quality of life, end-of-life-decisions

\section{INTRODUCTION}

Amyotrophic Lateral Sclerosis (ALS) is the most common motor neuron disease. It is characterized by progressive degeneration of upper and lower motor neurons, leading to progressive paralysis, dysarthria, dysphagia and increasing respiratory disabilities. The average survival after diagnosis is 3-5 years and most common causes of death are respiratory failure or dysphagia. Therefore, life-prolonging measures and especially tracheostomy might significantly increase survival $(1,2)$. As there is still no curative therapy available the main focus is palliative care aiming to improve ALS-patients' individual quality of life (QoL) and support caregivers (3). Moreover, it is reported that multidisciplinary integrated palliative care not only improves QoL but even prolongs survival 
$(4,5)$. On the one hand, physical symptoms such as pain, increasing swallowing and respiratory difficulties and restrictions in activities of daily living can at least be partially controlled by medication and support for everyday life, e.g., by the use of assistive devices. Potentially life-sustaining measures such as percutaneous endoscopic gastrostomy (PEG), non-invasive ventilation (NIV) and tracheostomy with invasive ventilation (TIV) can also improve QoL by controlling feeding problems or dyspnea. However, their initiation needs careful discussion, individualized decisions and patients' explicit and fully informed consent (6-9).

Data is sparse for other countries than Japan, but TIV-rates among ALS-patients seem to increase up to $20 \%(10,11)$. These numbers underpin the relevance of the complex and extremely difficult decision whether or not-and if yes, at which physical or psychological health status-life-prolonging measures should be terminated. The few studies on this subject describe that patients often decide to terminate TIV because of a subjective "loss of meaning in life" and poor QoL $(12,13)$. At best, this issue should be discussed and considered explicitly in patients' advance care planning after careful discussion (6).

On the other hand and in face of the fatal and progressive nature of the disease, palliative care for people with ALS needs to address not only control of somatic symptoms but also psychological, spiritual and existential aspects. Decision-making over medical care from the time of diagnosis until death is a cyclic process that should be guided by patients' autonomy and care has to be adapted to the changing needs of patients and their families. To meet these needs, intense communication between the affected persons and health professionals is essential (14-16). Communication is further described as crucial to sustain hope and reduce fear in palliative care (17).

Overall, dysarthria occurs in $80-95 \%$ of people with ALS at some point in their disease course, making them unable to meet their daily communication needs by means of natural speech $(18,19)$. We thus aim to provide an in-depth overview of the possibilities of HT-AAC technologies and their influence on, patient care, social life and QoL of severely disabled patients and caregivers, but also of their limitations. On this basis, we discuss the role HT-AAC use in palliative care for patients with ALS.

\section{IMPORTANCE OF HIGH-TECH AUGMENTATIVE AND ALTERNATIVE COMMUNICATION (HT-AAC) TECHNOLOGIES IN ALS}

In line with Janice Light's description of communication as "the essence of human life" (20), a qualitative study of McKelvey et al. (21) impressively described the frustration and sadness that patients and their partners experience as speech

Abbreviations: (HT-)AAC, (high-tech) augmentative and alternative communication; ALS, Amyotrophic lateral sclerosis; BCI, brain-computerinterfaces; CA, classification accuracy; ETCS, eye-tracking computer systems; FTD, frontotemporal dementia; (T)LIS, (total) locked-in-state; NIV, non-invasive ventilation; PEG, percutaneous endoscopic gastrostomy, QoL, quality of life; TIV, tracheostomy invasive ventilation. deteriorates: "That was probably the biggest hurt. She couldn't talk." Patients are often deprived of their ability to judge, experience a lack of control and a change of their social roles. The ability to communicate is strongly associated with patients QoL (22) and communication is seen as crucial for the adaption to terminal diseases such as ALS (23). Therefore, while verbal as well as nonverbal communication abilities deteriorate, augmentative and alternative communication (AAC) strategies and technologies become more and more important. AAC strategies in general are in place to support communication related to a large variety of issues, such as personal and medical care, social interaction and closeness, community involvement and employment, and to express personality and feelings $(18,21)$.

AAC might be no- or low-tech (gestures, facial expressions, handwriting, topic boards, alphabet boards, and eye-linking partner-supported systems) or high-tech with or without synthesized speech output (e.g., tablets, touchpads, head- or limb-movement-activated microswitch systems). High-tech augmentative and alternative communication (HT-AAC) technologies afford minimal or no head or limb movement and enable complex, caregiver-independent communication as motor abilities decrease $(24,25)$. Since the decision for TIV increases survival and therefore the length of HT-AAC-use (26) and considering the growing percentage of patients deciding for TIV, the need for HT-AAC will likely grow. The use of (HT-)AAC devices to support communication in different groups of severely disabled patients has been discussed since decades [e.g., (27)]. This review focuses on HT-AAC for severely disabled patients with ALS who depend on multimodal palliative care.

\section{TECHNOLOGY OF HT-AAC EYETRACKING COMPUTER SYSTEMS}

The most promising and best-studied HT-AAC devices are eyetracking computer systems (ETCS) which allow cursor control by eye movement. Eye movements are often the least fatiguing $(28,29)$ if not the only remaining volitional movements that allow communication in ALS (27).

Although the technology that drives eye operated speech generating systems has been modified over the course of the last 40 years, the underlying principles did not change much. All systems use infrared sensitive cameras, mostly based on complementary metal-oxide-semiconductor sensors nowadays and with an active infrared light source to illuminate the eyes. The systems primarily differ in the relative positioning of the infrared light source with respect to the camera lens axis. Systems with an infrared light source located very close to the camera lens axis make use of the bright pupil effect: the infrared light gets reflected on the eye's retina and produces a bright image of the pupil. Conversely, in systems with the infrared lights placed off axis the images received from the camera sensor generate dark pupils. In both systems the infrared light source produces additionally a bright reflection on the cornea (the glint), which is together with the pupil center used to calculate the pupil-glint vector $(30,31)$. This vector then serves to calculate the Point of Regard on a computer screen and thus can be used to type by 
means of a gaze sensitive on-screen keyboard or to drive other computer functions.

\section{ADVANTAGES AND PROMISES OF HT-AAC IN PALLIATIVE CARE}

\section{Acceptance and Usability of HT-AAC to Restore Communication Ability}

Several studies demonstrate the positive impact of ETCS-use for severely disabled people. First of all, acceptance and user satisfaction are reported to be high in ALS and traumatic brain injury $(32,33)$. Ball et al. (32) found in a study of 50 patients with ALS that $96 \%$ of those who were recommended AAC technology due to increasing communication disabilities accepted the device, either immediately or after some delay. The three main reasons for their decision for AAC were maintenance of communication, participation in community and employment. Patients who rejected AAC often suffered from frontotemporal dementia (FTD), which is in line with another study (18).

Patients use ETCS for a variety of activities such as face-toface-communication-even in groups-e-mail contact, internet access and other computer functions and programs as well as for environment control $(24,34,35)$. Regarding the increasing importance of social media, their access by HT-AAC is an additional valuable mean of communication, link to the outside world and thereby supports patients' social networks (36). Thus, HT-AAC can enable social and intellectual stimulation, independent leisure activities and the patients to express even complex thoughts. As AAC allow even severely disabled patients to communicate with less familiar caregivers, they enrich patients' possibilities in choosing communication partners.

Evaluation studies of HT-AAC-use show that once a functioning ETCS could be established, patients use it for several hours each day and report a high user satisfaction, preservation of communicative abilities and subjective indispensability of the device $(34,37)$. Interestingly, the worse patients' clinical conditions, the higher seems to be their acceptance of HT-AAC (38).

\section{Regain of Social Participation, Psychological Wellbeing and Quality of Life} In an interview study by McKelvey et al. (21) spouses reported that AAC technologies helped to maintain the emotional connection within families. What they additionally valued as a very precious function was that patients-with the help of their next of kin-could discuss philosophical ideas and author "last words" and thoughts to their families. The use of AAC devices even enables psychotherapy for severely disabled patients in order to reduce psychological distress and promote autonomy and self-esteem (39).

Several cross-sectional and two longitudinal studies found a positive association between higher psychosocial wellbeing or QoL and the use of ETCS $(25,34,38,40-42)$. The assumption of a positive effect on Qol is further supported by the findings that HT-AAC-use serves as an active coping mechanism, helps patients to express emotions and personality and to maintain social roles, participation in family and community and even employment $(21,43)$. These results are confirmed by the first study evaluating the association between QoL and ETCS use in ALS-patients in the locked-in-state (LIS) in a fully caregiverindependent manner by using ETCS-based assessment (44). Patients reported on average a high QoL and the study suggests that ETCS preserve patient autonomy and therefore psychosocial wellbeing particularly by enabling social activities, which patients named as the most important area of life for their QoL. A generally high subjective QoL in ALS has been reported before for less severely affected patients as well as for LIS-patients (45-47). It is discussed that psychological wellbeing might even modify disease course in ALS $(48,49)$.

Consequently it can be assumed that by enabling patients to stay mentally autonomous and realize their needs in terms of social activities and participation, encouraging successful adaption to the disease and thereby increase psychological wellbeing, HT-AAC might even have disease-modifying effects. This remains to be clarified in longitudinal investigations.

\section{Reduced Caregiver Burden}

Caregivers of ALS-patients report low QoL and high burden (50-53), which is especially true for tracheotomized patients and those in LIS $(8,44)$. The use of ETCS though is associated with reduced caregiver burden, probably by improving patient autonomy and making patient-caregiver-communication more effective (40). An interview-study of 34 family caregivers of ALS-patients reports a very positive attitude toward HT-AAC devices, an increased perception of social closeness and fewer difficulties in providing care due to the AAC-use. These benefits are greater for those with higher AAC technology skill levels (35). Corallo et al. (42) could demonstrate in a longitudinal study of 15 LIS-patients and their caregivers that enabling patients to communicate via HT-AAC reduced caregivers' anxiety and increased their vitality as well as social activity and social role functioning; results that highlight the positive value of HT-AAC supply also for the caregiver themselves.

\section{(Neuro)Psychological Assessment}

Another important issue is the use of HT-AAC for neuropsychological assessment, since neuropsychological test procedures usually require at least some motor or verbal skills and therefore become invalid for severely disabled patients. It is known that cognitive deficits affect a great proportion of all-ALS-patients (54) and can compromise their ability to judge and decide over their medical care and life-prolonging measures (see chapter Cognitive and behavioral impairment and its consequences for HT-AAC-use). Promising attempts have been made to develop ETCS-based test procedures of cognitive functioning $(55,56)$.

\section{IMPACT OF PATIENT AUTONOMY IN PALLIATIVE CARE}

The reported findings make clear that enabling complex communication independent of a "translation" by caregivers/next-of-kin and thus patient autonomy is crucial 
for the preservation of psychological wellbeing of severely disabled patients. Furthermore, HT-AAC have high implications for end-of-life-issues: First, the possibility to communicate might directly change patients' attitude toward life-prolonging measures, as Fager and colleagues explicitly reported for one LIS-patient equipped with a computerized communication system controlled by minimal head movements: "He was so encouraged [by the regain of his communicative abilities] that, when he entered the hospital with pneumonia, he changed his medical code status from 'do not resuscitate' to 'full code"' (57). In turn, we assume for two of the patients who were recruited for our study (44) but died before the assessment that an earlier supply with ETCS could have changed their decision against life-prolonging measures.

Second, caregiver-independent communication enabled through HT-AAC supply is crucial for assessing the patients' psychological condition and actual will and ensure selfdetermination of care. Advanced care planning and in general decisions over the medical care for severely disabled patients need a careful discussion of all relevant procedures, advantages and potential risks to ensure self-determination. This is specifically true for decisions to initiate or terminate life-prolonging measures such as PEG, NIV or TIV. It was mentioned above that the patients' self-rated QoL is often relatively high, moreover and importantly it is significantly underestimated by caregivers as well as the general population $(52,58,59)$. This is in particular noteworthy for patients in LIS: the average QoL of the 11 LISpatients in our study, self-rated via ETCS, was $81 \%$ while next of kin estimated patients' QoL to be only $63 \%$ and thus similarly low as their own self-rated QoL of $54 \%$ (44). It is not clarified yet which factors contribute in which extend to this significant discrepancy. However, there has been reported a "response shift" in the evaluation of their QoL by patients toward a higher value of social activities and a lower value of financial aspects, mobility and leisure activities $(47,60,61)$; a shift that patients' next of kin are apparently not aware of (44), maybe because it does not happen for them.

Furthermore, in the face of their shorter lifetime some patients gain a "deeper view" and a higher appreciation of life (62).

However, it must also be considered at this point that some patients may suffer a loss of awareness or insight in their situation or a reduced ability to judge it, as executive functioning (63-65) and social cognition including empathy are impaired in a proportion of non-demented patients (66-68); an issue that is further discussed in chapter Cognitive and behavioral impairment and its consequences for HT-AAC-use.

Irrespective of its causes, the contradictory assessment of patients' QoL by patients themselves and caregivers may have tremendous consequences on end-of-life-decisions and thus makes it essential to enable patients to communicate even complex utterances independently of their next-of kin or caregivers. Actually, LIS-ALS-patients themselves confirm that they are able to do so by means of their own ETCS but not without the device $(37,44)$. It is indispensable that patients' wishes concerning life-prolonging measures are not undermined. This is extremely difficult to assess and ensure, as communication structures in families and between health professionals and patients are hard to grasp anyway, all the more if one partner suffers from severe communication difficulties. We observed one case, in which the patients' wish for TIV probably was circumvented on hospital admission which caused her death (44).

Since the patients' will may change during disease course $(12,69,70)$, communication must be enabled at every time point in the progression of the disease and thus even if no head or limbmovement or natural speech is possible. This is emphasized by the fact that a significant proportion or even clear majority of ALS-patients is tracheotomized unplanned, e.g., as an emergency measure, and in a relevant amount of cases without explicit informed consent of the patient $(8,71)$. As this can obviously be avoided by early, careful and detailed advanced care planning as recommended by Oliver et al. (15), the valid assessment of patients' will has to be striven for at each point of time. It was argued before that this approach will also disburden caregivers from vital decisions for their loved ones in the fear of making them against their actual will. Parallel to ensuring the patient's autonomy, the highly burdened caregivers need to be involved in medical decision making $(6,15)$ and to receive specialized practical and psychological support $(72,73)$.

\section{LIMITATIONS AND PITFALLS OF HT-AAC-USE AND-SUPPLY}

Nakayama et al. (74) suggested a definition of five stages of communicative abilities of TIV-ALS-patients that is of high value for the prediction of impaired communication: patients who can communicate without any high-tech devices are classified as stage I, patients with communication difficulties that can be overcome by use of HT-AAC technologies to a varying extent as stages II to IV and those who cannot communicate at all as stage V. Predictors identified for the progression from stage I to a higher one and therewith predictors of severely impaired communicative abilities are oculomotor dysfunctions, TIV and full quadriplegia.

This model indicates that despite the diverse possibilities and promising research results by far not all patients suffering from advanced ALS and other conditions that affect communication abilities are supplied with an HT-AAC device or respectively gain a successful restoration of their ability to communicate by means of HT-AAC. Beside the three important reasons for this lack identified by Nakayama et al. (74), there are several more which can be assigned to the three main components of the AACacceptance model by Lasker and Bedrosian (75): factors of the user, the environment and the device.

\section{Factors of the User}

\section{Eye Pathologies and Eye Movement Dysfunctions}

A number of ophthalmologic diseases and oculomotor dysfunctions can complicate ETCS-use. Although oculomotor function is typically spared from the effects of ALS, dysfunctions occur in a proportion of the patients and particularly ophthalmoparesis in those with prolonged survival $(74,76)$. Certain deficiencies like slowed down saccades or ptosis can be accommodated by some ETCS, but others like eye movement 
paralysis as well as further problems such as glaucoma, gaze tiredness or problems to keep the head still can make it difficult or even impossible to use ETCS (34).

While normal astigmatism can be usually very well compensated during the calibration process, more severe and irregular deformations of the cornea may pose a challenge for accurately determining the user's gaze, since this may affect the way the infrared is reflected from the eye. If only one eye is affected, some ETCS allow focusing only on the eye without cataract. Nystagmus, a condition characterized by repetitive, uncontrolled eye movements, is another factor that can make it impossible to use ETCS because nystagmus (a) can impede calibration as a user is not able to hold its gaze still for a prolonged time and (b) even if calibration is possible, users will have difficulties resting their gaze on a button for a long enough period of time. Another condition that can interfere with ETCS use is strabismus. While single eye strabismus can as well be compensated by focusing only on the non-affected eye and eventually applying an eye patch on the other one, alternating strabismus cannot be compensated for by ETCS as it is not possible to determine which eye is directed at any given point in time.

Another frequent obstacle in clinical practice are spurious reflections from glasses since they may, depending on the location of the reflections, interfere with the corneal reflection. Although contact lenses are usually no problem, for hard contact lenses the corneal reflection sometimes happens to lye partly on the circumference of the lense and thus only partly on the cornea.

Electrooculogram-based eye-computer interfaces might overcome a few of the limitations of ETCS since they are not influenced by lighting or the physical conditions of the eyes. However, this method also requires the users' abilities to control their eye-muscles and is moreover less precise than ETCS (77). Microswitch-activated systems that rely on any residual muscular activity can be another option (78).

Irrespective of which HT-AAC device is chosen, there is still the risk that patients progress to a total locked-in-state (TLIS) and thus to stage IV of communication abilities (74), since TLIS is defined as the complete loss of muscle control including the eye muscles and therefore any valid ability to communicate needs (79). This is obviously an extremely burdening situation for caregivers and health professionals. The overall prevalence of TLIS is difficult to determine, but Hayashi and Oppenheimer (80) reported a prevalence in ALS-patients on TIV of $11.4 \%$.

\section{Psychosocial Factors}

Certain attitudes and needs are potential reasons for the refusal of HT-AAC by patients. In her qualitative study on the nonacceptance of HT-AAC Murphy (81) reported on this matter that some did not use their device because they desired using their own voice as long as possible. Communicating via a device was perceived as just "not the same." In line with another case study, patients preferred the higher social closeness and the direct interaction of face-to-face-communication $(81,82)$. Furthermore, patients reported a "shared understanding" in everyday communication with familiar partners that makes HTAAC devices dispensable. However, referring to the stage model of Nakayama et al. (74), all of these patients were still in stage I, so still able to communicate via speech which often changes as the disease progresses (81). Low-tech and face-to-facecommunication-if (still) possible-might be more effective and comfortable for communicating quick needs and for interacting with familiar partners, while sharing detailed information and communication with less familiar partners requires HT-AAC $(75,83)$. In summary, advantages of different communication modes depend on individual abilities, aims of communication and familiarity of interlocutors.

An additional difficulty is the optimal timing of AACinterventions, thus the decision at which stage of communication ability or impairment HT-AAC devices are introduced and established. On the one hand, patients and caregivers often don't want to be confronted with predictable deficits before speech becomes intelligible and thus delay the decision about HT-AAC use $(18,84)$. On the other hand, timely referral not only ensures punctual delivery of the device but also better learning conditions for the patient $(14,18)$.

Age, education and computer experiences might also influence HT-AAC acceptance. Actually, samples of the reported investigations on ETCS-acceptance and impact on wellbeing $(25,40,44)$ were relatively young and highly educated compared to average ALS-patients. However, Caligari et al. (25) found no influence of education and computer experience on ETCS acceptance or benefit. Considering age as a potential factor, Spataro et al. (34) reported regular users to have a younger age of disease onset compared to irregular and non-users.

Cognitive deficits are another important influence factor on the usability of ETCS. While the progression rate of cognitive deficits to a full blown dementia in late stage ALS is not known, up to $10 \%$ of ALS patients suffer from FTD at any specific time (54) and cases of the development of severe dementia under TIV are known. Apart from that, studies describe cognitive deficits to be relatively stable over the disease course and observed good cognitive functioning in patients with late-stage ALS (85, 86). Nevertheless, mild to moderate cognitive impairment is highly prevalent in ALS, which is described in depth in chapter Cognitive and behavioral impairment and its consequences for HT-AAC-use.

\section{Factors of the Environment Supply and Professional Support of HT-AAC-Use}

The environmental conditions are probably the most vulnerable aspect of HT-AAC-provisioning for severely disabled people, regarding to begin with the supply of the devices and the continuous individual support to ensure their optimal usability. First, clinicians involved in the care need to be aware of HT-AAC devices and their possibilities and-concerning the mentioned issue of timing of supply-must support the patients' decision process on the use of such devices in an active but also sensitive and properly timed manner. This can be considered a difficult $(84,87)$ and important challenge, especially in view of the finding that lacking referrals by physicians are a frequent reason for delayed supply with HT-AAC devices (84).

Second, funding and availability of devices can be an issue as the health care system of many countries do not or only partially 
finance (HT-)AAC devices. The national health system in the United States started reimbursing AAC in 2001, but application is an exhausting and time consuming process (18). As Donegan et al. (88) report, the national health service of Italy started providing ETCS for ALS-patients several years ago because of increasing awareness brought by the research, but this is not consistent practice. For Germany, Funke et al. (89) found as a result of a cohort study on a case management program for ALSpatients that only $61 \%$ of AAC devices procured by the treating neurologists were finally delivered to the patients, which might be in fact an overestimation for the general population since the study was conducted in specialized ALS centers. The main cause of failed provision with a HT-AAC device was rejection by the health insurance, followed by rejection by the patient and patient's death. The mean latency of provision was 93 days, a long period of time for people not able to communicate without the device. The authors speculated that especially decisions over expensive assistive devices are guided by financial considerations at the expense of patients' wellbeing (89).

Moreover, provision of HT-AAC devices is not only costly but also difficult to install as they need to be adapted to each individual user. Service providers need to provide training of circa $5 \mathrm{~h}$ (24) and ongoing support, trouble-shooting and individual customizing over an extended time period (18, 33). Insufficient training is often reported to be a reason for helplessness and non-use of HT-AAC $(33,75,81)$. Caregivers need detailed step-by-step-instructions and intense training too, because they serve as indispensable HT-AAC facilitators (90). AAC success is reported to depend on caregivers concerns, attitudes and awareness $(81,91)$ and caregivers with higher skills report higher reward (35).

To avoid unequal service provision and optimize the timing of AAC-interventions, regular assessments of patients' communication abilities by trained and independent AACexperts are recommended (84). At best, an assistive technology clinic as described by Casey (92) is created, combining expertise, time and material resources and the ability to test and individually customize devices. This might also offer a solution for the challenge of optimal timing of AAC-interventions, by allowing patients to get familiar with different technologies and to face upcoming communication problems step by step (14). It is recommended that the communicative abilities of patients suffering from diseases leading to foreseeable disabilities are regularly evaluated by trained health professionals such as speech language pathologists (93). Patients should be referred for AAC assessment when their speaking rate falls below 100 to 125 words per minute or when patient or listener perceive the communication effectiveness as decreasing $(18,94)$.

\section{Influence of Family Caregivers or Next of Kin}

An issue that has not been addressed systematically in the literature until now is that caregivers might experience negative aspects of patients' HT-AAC use. The ability to communicate detailed thoughts and wishes, also with third parties, might lead to increased feelings of burden-especially in combination with a decision pro NIV. This was possibly the case for one patient in a study by Linse et al. (44), in which the family returned the ETCS without stating reasons and despite it was working well and the patient expressed the wish to use it. Evaluating the perceived usefulness of ETCS, next of kin also reported some critical issues, e.g., an increased burden since patients started to use the ETCS (37). Reasons for this higher burden need to be clarified. It is conceivable that it is related to patients' increasing duration and severity of ALS, to the social-communicative or technical requirements raised by the ETCS itself or to the fact that the patient is now able to communicate his wishes that she or he want to be satisfied by the next of kin.

However, family caregivers of severely disabled patients' are in general a highly burdened and overloaded population that has to be considered and supported in the palliative care (15) and in particular concerning patients' supply with HT-AAC. Beside and in connection with the discussed low quality of life and wellbeing of next of kin, it is known that severe diseases like ALS have far-reaching effects on a social system beyond the index patient; and it is therefore essential to study impacts on the caregivers and their perspectives separately from patients' perspectives (89). While HT-AAC technologies can help to prevent the patients' social networks, assuming the role of the caregiver often results in a loss of freedom and of time and energy for self-care as well as in a change of life plans. The size, quality and changes of their personal social network have to be investigated in future to minimize the negative consequences of the disease on family caregivers $(95,96)$ and in consequence to counteract unfavorable influences on patient's decision, e.g. for or against use of HT-AAC devices.

\section{Factors of the Device}

There are also several issues related to the HT-AAC device itself that can hinder its optimal use. Particularly for ETCS, accuracy of older devices can be insufficient and complex calibration and setup procedure can complicate the handling (24). The bad quality of the voice output is another issue occasionally regarded as problematic by patients as well as caregivers $(21,43,81)$. Voice banking and voice conversion techniques lead to hope for more personalized speech synthesis in the future (97). However, we are not aware of a single study investigating the value of this voice banking technique. From own experience it can be reported that patients themselves experienced their recorded voice not as their own. In contrast, next of kin do so but have difficulties accepting that this technology device talks with the voice of the patient. Finally, independent of voice banking and concerning the authenticity of the voice, the speech output does not adapt to the content of the words in terms of emotion, thus e.g., joy and crying do not sound differently.

Another technical drawback of the currently used eyetracking technology, independent from individual factors of the patient (e.g., oculomotor dysfunction), is the sensitivity of the infrared light sensitive camera to ambient infrared light, because it immensely reduces the usefulness of the devices in outdoor settings. Only reliable and portable devices that can be adjusted e.g., to a variety of lightning conditions can ensure the use of HT-AAC in different settings $(40,43,81)$. Another relevant difficulty in ETCS-use is the "Midas touch problem." It describes the frequent phenomena that the focus of attention is not in 
accordance with the users' direction of gaze, which results in nonintended commands like for example a wrong selection of letters (98).

Ideally, switching of access methods (e.g., from touch to joystick to eyegaze) with one device and one easy-to-learn "intuitive" software as well as the setup of different individually tailored features (e.g., internet and mobile phone access, environment control, leisure activities) should be possible with one HT-AAC device. These options would allow to adjust the device to the patients' changing needs and physical abilities and enable communication with different partners in different settings $(18,91)$. High quality products should be employed as technical problems and learning difficulties reduce the motivation to use HT-AAC even though it is generally wished and needed (38).

\section{COGNITIVE AND BEHAVIORAL IMPAIRMENT AND ITS CONSEQUENCES FOR HT-AAC-USE}

As suggested earlier, relevant behavioral and cognitive impairment under the threshold of (frontotemporal) dementia but also caused by frontotemporal dysfunction is a common and critical feature of ALS $(99,100)$. Guided by FTD-diagnosis though, there is a distinction between (non-dement) ALS with behavioral impairment (ALSbi), with cognitive impairment (ALSci) and with a combination of both (ALScbi) (99).

Cognitive impairment in general is reported to affect between 30 and $40 \%$ of the ALS-population (54, 64, 101), although estimations of prevalence vary considerably; an inconsistency that is probably partly explained by the considerable heterogeneity of first those deficits $(63,99)$ and second of the methods used for their assessment (65).

Nevertheless, impairment is consistently reported for the broad cognitive domains of executive functions, language and memory $(54,63,64,102,103)$. Recent meta-analyses additionally confirmed deficits in social cognition as another prominent feature of $\operatorname{ALS}(54,67)$. Furthermore, different behavioral changes can be observed in ALS-patients (104).

Concerning consequences for HT-AAC-use, Beukelman et al. (18) interestingly reported for patients with mild cognitive deficits that all who wanted and needed AAC for communication were able to use it. Anyway, in view of the cognitive, linguistic and social demands of communication, the cognitive and behavioral impairments due to ALS must be assumed to have important implications not only for communication ability in general (105) but also by (HT-AAC)-use in particular. This is most obviously for deficits in language comprehension and expression.

\section{Language Impairment}

Language function is a very broad domain, but Beeldman et al. (54) analyzed that studies reporting its impairment in ALS often operationalized it as the ability to name objects in Visual Naming Tests, which are used as an important diagnostic tool for aphasia $(106,107)$. Naming deficits probably based on a general impairment of basal word finding processes seem to be a typical aspect of language dysfunction in ALS (108). The capability to communicate effectively and comprehensible by means of HT-AAC can be further critically aggravated by a lack of comprehension and thus errors concerning semantic, syntax or grammar of language. Such problems were found to affect almost $50 \%$ of all ALS-patients (109), already in early disease stages (110) and even when executive functioning is intact $(110,111)$. They with single word and in particular verb processing $(109,112)$ and also with continuous speech production in form of e.g., less produced words, shorter utterances, and incomplete sentences $(110,111)$.

A function especially often reported to be strongly impaired in ALS is (phonemic and semantic) verbal (letter and category) fluency $(54,109,113)$. Deficits of fluency in comparison to healthy controls are even present when performance is controlled for patients' reduced motor speed $(65,114)$. Such deficits can indicate a limited access or principal limitation of the mental vocabulary (115) or a broad semantic deficit (108) and therefore a serious restriction of communication ability.

Although these language function impairments were determined in spoken or written/typed language, they should as well compromise language production by means of HTAAC devices in terms of comprehensibility, effectiveness, completeness, subjective meaningfulness and value for the recipient. Patients' deficits of language or speech comprehension should hamper communication anyway, irrespective of the means they use for it.

\section{Executive Dysfunctions}

Impairments of language function in ALS are reported to be strongly associated with executive dysfunctions $(64,109)$, some experts even construed them as a pure consequence of the latter (114). Executive function is the most extensively researched cognitive domain in ALS (109) and a population-based study and a meta-analysis confirmed highly prevalent deficits for a variety of standard neuropsychological tests in non-dement ALSpatients $(63,64)$. A significant lower performance compared to healthy subjects was also found for a complex measure of executive functioning with high ecological validity, controlled for patients' reduced motor speed (65). Generally spoken, executive functions are a group of higher cognitive functions with a crucial role for controlling basal cognitive functions (116) like attention and memory. Hereby, they are necessary for sorted and goaldirected behavior (117) in situations when automated, intuitive or routine behavior is not possible or inadequate (118) and assumed to be of great importance for response initiation and motivation (108). They are therefore obviously important for social interaction and communication (via HT-AAC).

Specific executive functions that are repeatedly reported to be impaired are shifting $(114,119-121)$ and working memory (114, 122-124), while patients show deficits for explicit measures of inhibition control in some investigations (124) but not in others (121).The high prevalence of verbal fluency deficits is mentioned above, but important again at this point. This is because tasks of verbal fluency and shifting are considered as measures of the executive function of cognitive flexibility and therefore concern the essential interpersonal ability of perspective taking 
(117). Since working memory is a precondition of "making sense of written or spoken language whether it is a sentence, a paragraph or longer" [(152), p. 143], deficits of ALS-patients can be assumed to make communication difficult. This is especially true for communication slowed down by HT-AAC-use and for such dealing complex issues. The latter also applies to an impaired ability of (abstract) reasoning which is reported to be common in ALS-patients $(65,125)$ and a cause of severe language comprehension deficits (126). All these deficits can be suspected to interfere with the ability to judge, which Flaherty-Craig et al. (125) directly assessed through an established cognitive battery and found to be impaired in a clinical relevant extent in 35\% of the non-bulbar and over $50 \%$ of bulbar-onset-ALS-patients.

Taken together, executive dysfunction common in ALSpatients can be presumed to limit or rule out a clear, stringent, reliable, valid, effective, empathic or purposeful communication that is satisfying for both the patient and interlocutor, even when the patient is cognitively able to operate the AAC device. This high impact is supported by the negative association between subjective executive dysfunction and wellbeing of ALS-patients' caregivers (127).

\section{Social Cognition Deficits}

Some of these aspects of successful communication should be importantly influenced by social cognition function as well. This domain includes the abilities to perceive, identify and understand, interpret or attribute social situations and other's cognitive and emotional states and to choose on that basis an appropriate reaction $(67,128,129)$; abilities with an obvious importance for successful communication and social interaction and integration Deficits in this domain affect patients with ALSbi and ALSci $(67,99,130)$, are associated with executive dysfunctions (67) but also occur in ALS-patients without those $(130,131)$. The results of a recent meta-analysis even suggests social cognition to be stronger compromised than executive functions (54).

Emotion recognition and Theory of Mind are most frequently studied in ALS-patients (67). Meta analyses report moderate deficits in facial emotion recognition for anger, sadness and disgust (132) and for disgust and surprise, respectively (67)-an inconsistency that can probably be explained amongst others reasons by the heterogeneity of the used measures and of the clinical and cognitive features of the mainly small study samples. A recent study confirmed deficits of correct emotion recognition in face as well as in voice even for ALS-patients with otherwise unimpaired cognitive abilities, but particularly for complex emotion expressions (133). Irrespective of the specific (negative) emotions though, a lacking ability of identifying and consequently attributing them correctly and responding to them adequately can be considered to be very dissatisfying for patient and interlocutor, causing frustration and interpersonal conflicts; all aspects possibly affecting HT-AAC use and validity of QoL measures of locked-in patients which has not yet been studied.

This is just as true for deficits in Theory of mind, a complex concept that includes the ability of perspective-taking (ToM-PT) according to understand other persons' behavior by representing their emotions and cognitions, e.g., thoughts and beliefs (134,
135). In accordance with findings for cognitive flexibility reported above, meta-analyses proved a lower performance of ALS-patients in different measures of ToM-PT compared to healthy controls $(67,132)$. This finding is confirmed by a recent study for early-stage ALS-patients (136) while again nothing is known yet in very advanced stages. Deficits are repeatedly reported to be more pronounced in ALS with bulbar onset $(125,132,136,137)$ and therefore in the subgroup of patients that is more frequently or earlier dependent of HT-AAC support for communication.

Considering that human behavior is crucially motivated and determined by emotional and social goals (128), the quantity, subjective quality and thereby value of communication can be assumed to suffer under discussed deficits. This is true for the ALS-patients themselves but especially for their next of kin, as the deficits potentially compromise the relationship, intimacy and their wellbeing and quality of life; like it is known to result from ALS-caused changes in behavior, cognition and communication in general (138).

This assumption is importantly supported by findings of changes in social behavior observed by primary caregivers: 70\% showed an increased self-centeredness and a reduced interest for the feelings of others persons (139). A study by Fisher et al. (66) further suggests a lack of patients' insight into their social cognition and consequently social behavior impairment and therefore a lack of awareness of its effect on communication and interaction partners, which can be assumed to even increase the burden due to this impairment for the next of kin.

Additionally, the negative impacts of social cognition deficits can be presumed to be strengthened by general characteristics of the disease and of communication via HT-AAC: mimic and gestures are strictly limited, eye contact is not possible while speaking or to say writing, communication is slowed down immensely and the voice output does not transport any emotions.

\section{Memory Impairment}

Memory functions have been studied very frequently in ALS and deficits were found by a lot, although not by all studies (99). Focusing their importance for communication ability, immediate $(54,63)$ and delayed verbal memory are often severely impaired in ALS, also again when controlled for reduced motor speed (54). Recent findings suggest that such deficits are independent from executive dysfunctions (140). Immediate and delayed prose memory (saying recall of stories) as a special type of verbal memory was found to be affected in over $20 \%$ of highfunctioning ALS-patients (141). In accordance with word-finding and naming-deficits, disturbances in sematic memory seem to affect more than the half of the ALS-population (142).

\section{Behavioral Changes}

Despite cognitive deficits-although not independent from them and often hard to distinguish (108)-frontal lobe dysfunction is associated with various significant behavioral changes and neuropsychiatric symptoms in ALS, frequently disinhibition, mood disturbances, and in particular apathy (104, 108, 133, 139, 143-147). Regarding the issue of patient's motivation to communicate, studies by Lillo et al. $(124,143)$ for example found 
significant symptoms of apathy in ALS, particularly a crucially limited motivation in $80 \%$ and a significant apathy in about $40 \%$ of the 92 enrolled patients (143). These syndromes were reported by caregivers in the questionnaire CBI-R (148), which assesses motivation mainly according to social motivation, e.g., as the motivation to stay in contact with significant others, show affection to them and be interested in their issues and concerns. Therefore, this finding is in accordance and probably directly connected with deficits of social cognition and behavior illustrated before. For other measures, caregivers report a clinical relevant apathy for up 40-60\% of the ALS-patients (139, 146, 147). The significance of apathy for communication and social interaction is in accordance with the finding that caregivers and next of kin report a reduced initiation of conversations by the ALS-patients compared to premorbid behavior $(66,146)$ to show a reduced initiation of conversations. It can be moreover assumed that a lack of motivation up to apathy might especially affect communication by means of HT-AAC, regarding the high effort that is required for training and use of such devices for communication purposes, e.g., choosing every letter of a message via eye movement. Not surprisingly, apathy is strongly associated with caregiver burden (133).

Depressive symptomatology is another factor that must be considered to compromise patients' motivation to communicate. A clinical relevant severity is reported for $30-60 \%$ of the ALS-patients $(45,51,149,150)$. Equivalent to dysexecutive syndrome, behavioral changes in ALS are negatively correlated with caregivers' psychological wellbeing (147).

\section{Consequences of Cognitive and Behavioral Dysfunctions for HT-AAC}

In summary it can be argued that frequent cognitive and behavioral deficits and impairments in ALS have a negative effect on communication in general and in particular by means of low and high tech AAC. Therefore, they form a mayor challenge for adapting those devices to the individual patient with the aim of maintaining and supporting subjective value of and motivation for communication in both patients and communication partners. Changes in cognitive function should thus be monitored continuously, on the one hand to support this continuous adaption process and on the other hand to prepare patients and next of kins for upcoming challenges and (further) limitations of communication possibilities (91).

In the case of LIS, this objective is particularly challenging and at the same time very important to be achieved. Challenging because it requires motor and speech free tests and thus emphasizes the significance of developing eyetracking-based neuropsychological tests. Important, first because a restriction of direct communication via HT-AAC due to cognitive or behavioral deficits cannot or hardly be compensated by indirect communication in form of, for example, gestures and mimic. Second, because tests suitable for LIS-patients are needed to understand the natural history of ALS; referring to the Braak staging system in particular (151-153), this means to understand whether the progressive pathological involvement of brain structures, including such responsible for cognitive functions especially in late ALS-stages, continues also in the stage of LIS until TLIS. Third, because of the relevance of cognitive impairment for the highly important conclusions from discrepancies between patient's and next of kin's opinion concerning QoL and life prolonging measures. Concerning possible adaptions of HT-AAC devices for communication purposes to cognitive limitations, language dysfunction is-at least for mild to moderate severity-most likely the easiest part to compensate by high-tech devices. (Individualized) word prediction and word and sentence templates can facilitate language production and comprehension. A possible adaption of HT-AAC devices e.g., for LIS-patients with aphasia is the use of a symbol-based interface, which allows patients to express at least basic needs and wants and to control technical devices like TV, radio or lights.

However, deterioration of cognition can make the use of HTAAC impractical (18), in particular when patients progress into a FTD. It can be additionally assumed that frontal dysfunctions adversely interfere with the patient's motivation as well as the ability to judge the need for using HT-AAC devices for communication, based on a lack of insight e.g., in the noncomprehensibility of the own spoken language. This idea is indirectly supported by data suggesting an association between cognitive and behavioral impairment and low compliance with treatment in ALS (145).

Impaired cognitive and especially high cognitive functions like reasoning and social cognition that might crucially limit the ability to judge play moreover an especially critical or even devastating role when it comes to decisions over lifeprolonging measures (108), concerning reliability and validity of such decision in view of the discussed importance of HTAAC for making them autonomously. This is particularly true when patients' and next of kin's opinions in this matter diverge, considering the consequences of such decisions also for the family and the patient's beloved ones.

The authors believe that it is therefore highly important to clearly diagnose cognitive and behavioral disturbances also in advanced disease stages including LIS. Having a clear diagnosis of dementia or cognitive or social impairment enables the responsible care takers or medical doctors to draw the right conclusions. On the side of the caretaker, this can mean to correctly interpret the patient's unsatisfying (e.g., diminished or non-empathic) communicative behavior, this is to say as a consequence of the disease, which can be relieving. Discussed findings of rejection of ETCS devices by family members and their higher burden after the patient's supply with the communication device $(37,44)$ support this idea. On side of the caretaker and the attending physicians, drawing the right conclusions might also mean to decide to limit lifeprolonging measures. Concerning such decisions with regard to the patient's will, cognitive diagnostic and an earliest possible psychoeducation for patients and next of kin/caregiver about the frequent cognitive and behavioral deficits of ALS is important: first, to emphasize the need to continuously clarify and record this will in written (e.g., in a patient decree), since cognitive impairment might inhibit a reliable or valid decision at some points; second to allow patients and their families to take in 
account possible severe cognitive decline in future as an explicit factor for such life-prolonging/ending decisions (e.g., the will to end life prolonging measures in case of FTD or when the patient is not able to communicate via HT-AAC anymore).

\section{BRAIN-COMPUTER INTERFACES}

Discussed limitations and shortfalls of ECTS systems as means for communication and environment control raise the question whether there are alternative technological HT-AAC approaches. Brain computer interfaces (BCI) could in theory be one answer, particularly for the mentioned subgroup of (long-surviving) ALS-patients in whom the usability of ETCS is compromised by oculomotor dysfunctions (76), gaze fatigue (154) or the loss of eye movement control in TLIS (155). BCI systems enable e.g., computer operation by voluntary modulation of one's own brain activity which is decoded into commands (e.g., selection of an item) without requiring any motor control (156-158). They are therefore considered a promising communication tool for advanced ALS or LIS-patients, respectively (159-162) and the only remaining option for TLIS-patients (163) or those with severe gaze dysfunction in general (82). It is another advantage over ETCS systems that BCI systems don't require still and strict frontal positioning to the screen (164).

While invasive BCI methods like intracortical electrodes have been primarily studied in animal research (165) and infrequently in tetraplegic patients (166), a number of noninvasive BCI systems has been evaluated in severely paralyzed patients including ALS-patients in (T)LIS $(98,160,162)$. The majority of these systems have been developed for spelling or writing or texting (167) which is allowed by selection of letters, words or phrases presented on a screen (98).

In this context, reviews valuate non-invasive $\mathrm{BCI}$ based on EEG as a practicable, promising and the most widely used approach $(98,168)$. Also ALS-studies provide evidence for the principle feasibility of such systems for a relevant proportion of patients. Those BCI devices are based on shifting of particular brain responses measured as EEG-parameters: slow cortical potentials (169-171), sensimotor rhythms (SMR) $(155,172,173)$ and the event related potential P3 (164, 173-181).

Communication is one of the BCI-functions that ALS-patients are mostly interested in (182) and with the focus of this review on the importance of communication in palliative care and thus on spelling BCI systems, P3 is the most frequently used and studied EEG parameter (98). The principle of most (P3-)BCIspelling protocols is the following (98): an e.g., $6 \times 6$ matrix of items, usually letters, is presented on a screen and the patient is instructed to concentrate on the target item. Different rows or columns flash rapidly in succession. The P3 can be measured about $300 \mathrm{~ms}$ after the item flashes and by averaging the P3amplitudes following each flash, the target item can be identified [e.g., $(173,175)]$.

Usual objective evaluation criteria for such BCI are the effectiveness, i.e., classification accuracy (CA) defined as the "percentage of correct target selection" (183) and the efficiency (spelling speed). People with ALS declare a CA-threshold of $90 \%$ as satisfying (184). On this basis, all of the 20 ALS-patients in a recent study by Guy et al. (164) achieve a satisfying CA in the simpler task of copying a text ("copy spelling"), although it was lower that $90 \%$ for writing a text of their choice ("free spelling"). Anyway, patients reported an overall high user satisfaction (average 8.7 on a 10-point-scale). However and importantly, dysarthria was no inclusion criteria for the study, no subject was defined as (T)LIS and all showed unimpaired gaze control. This is in accordance with a mean CA of $92 \%$ reported by Pires et al. (179) for a classical spelling paradigm, whereby they included almost exclusively early-stage ALS-patients with even lower physical disability. A study of more severely motor impaired but also visually unimpaired ALS-patients $(N=14)$ only reported the maximum accuracy: it was circa $96 \%$ and did not differ significantly between patients and age-matched controls (175). In a previous study conducted by the same research group, 17 of the 25 enrolled patients achieved a high accuracy (average CA 92\%), but an accuracy below $40 \%$ for the remaining 8 patients indicates no usability of the BCI for communication; importantly, the latter patients all suffered from some type of visual dysfunction (176).

Overall, however, most studies report for ALS-patients with varying disability-levels and without controlling for visual deficits accuracy-rates that fall significantly below the $90 \%$ threshold $(155,170,172-174,181,185)$. This is in line with the average CA of $73.7 \%$, reported in a meta-analysis by Marchett and Priftis (183). Although higher spelling accuracy for able-bodied/healthy controls than for patients is reported (186), no evidence for a worse performance in ALS-patients with higher compared to those with lower physical disability is provided by very few studies with a sufficient sample size for analyzing this influence $(172,175,176)$. For (T)LIS-patients in particular though, there are only few and only case studies; two of them actually found high and stable effectivity of and satisfaction with a P3-BCIsystem for spelling (180) and painting (187), while one reports several unsuccessful trials of implementing a BCI in one patient transferring from LIS to TLIS (163).

An efficacy-related problem that would crucially compromise the BCI-usability in the context of palliative care for patients with such a quickly progressing disease like ALS are the very long training sessions required for reaching outlined accuracies (179). Another practical issue would be the long time that is needed to set up an EEG-BCI (164).

With respect to efficacy in potential future everyday use of $\mathrm{BCI}$ arises another main problem: the consistently reported low efficiency of spelling, i.e., in real-life use the slow potential communication speed. While ALS-patients indicate a spelling rate of 15-19 words per minute as satisfying (184)with a word is standardized to consist of five letters on average (188)-rates in recent P3-BCI-studies range between 2.1 words and 5.0 words $(164,175)$; and are even much lower (one letter, i.e., about 0.2 words per minute) for EEGsystems using SCR (171) and SMR-modulation (189). This problem is qualified by the patients mostly high satisfaction with BCI though $(164,171)$-a finding which supports that speed is less relevant for (T)LIS-patients than the possibility to communicate at all and in a reliable manner (180, 184). 
With regard to obligatory decision in palliative care and particularly those regarding life-ending-choices, even a BCI for yes/no-questions could be crucial for these patients without any other possibility to express their needs and decisionsbut a very high validity and reliability would be even more essential for this purpose Chaudhary et al. (162) were the first to evaluate a BCI for yes/no-answers in 4 TLIS- or patients transferring from LIS to TLIS, which relies on measuring change in frontocentral hemoglobin. The correct-response rate about $70 \%$ is still very unsatisfying although it could be valued as a promising base for further developments. In conclusion of this chapter it is important to note that a lot of the described pitfalls (see chapter Limitations and pitfalls of HT-AAC-use and -supply) and especially those due to cognitive impairment (see chapter Cognitive and behavioral impairment and its consequences for HT-AAC-use) account for BCI use as well.

\section{FUTURE DIRECTIONS}

From the reviewed literature it can be concluded that there is tremendous need for further research on the impact of HTAAC, technical progress of the devices and for an increased awareness of upcoming opportunities and the importance of communication on wellbeing by professionals caring for severely disabled patients and by policy-makers.

\section{Future Technological Developments}

A main obstacle for mobile use of ETCS is that they are bound to be used in conjunction with a computer screen. Eyetracking devices are typically mounted at the bottom of the computer screen, on which the user interface, e.g., an on screen keyboard, is displayed. In the near future with advances in augmented and virtual reality, head mounted systems with built in eyetracking capabilities may be applied. In addition to the advantage of being more portable, a see-through display would have the benefit of allowing the user to look at its communication partner and vice versa during conversation. In nowadays systems the computer screen is blocking the line of sight between the two partners, leading to subjectively reduced closeness as described above [e.g., (190)]. In order to reduce the sensitivity of ETCS to adverse lightning conditions, non-infrared based camera approaches may be used in the future, although they have not yet provided the level of accuracy that is needed for good gaze control.

We conclude from the discussed reports that existing (P3-)BCI systems for spelling/communication purposes do not allow and are not suggested for use in standard palliative care of ALS-patients at this point of time, especially in light of patient's quite high expectations on BCI-use (182). Concerning on the one hand patients that are (still) able to use ETCS, this conclusion supports the statement of Marchetti and Priftis (183) that (P3-based) BCIs for spelling still have many disadvantages and no clear advantage that would feature them as an alternative communication tool in daily use. It is however important to note already existing modifications of visual stimuli presentation $(174,179,185)$ and technical improvements for existing BCIs (177) that increase their accuracy significantly. Kaufmann and colleagues (185) for example could increase brain responses and consequently CA by integrating well known faces in the matrix in addition to the letters.

Concerning on the other hand ALS-patients that can't use ETCS anymore, BCI systems need to be primarily more effective and secondarily more efficient than they are at the moment, but would be then highly significant for this patient subgroup. Moreover, concerning TLIS-patients as well as the evidence for lower spelling accuracy because of visual problems, there is an indication for non-visual BCIs. Auditory or tactile BCIs exist, but are less widely studied up to now $(191,192)$. A case study of a LISpatients found clear superiority of tactile modality (185), while a comparison between a visual and equivalent auditory P3-system indicates the latter as a still less accurate but still promising option for LIS- and TLIS-patients with visual deficits (155). In accordance with that, a LIS-patient with subjectively worsening gaze control expressed in a case study of Käthner et al. (82) his preference for an auditory BCI over ETCS, although the latter showed significantly higher accuracy rates and communication speed.

BCI are therefore an important field of research with regard to the objective to secure self-determination and QoL in every, including the terminal phase of life of patients with most severe disabilities. So far, very few case studies explored BCI usability outside an experimental setting $(187,193)$. One of these studies though even found evidence for a relevant positive impact of BCI-use for spelling on QoL of a single TLIS-patient (193). Future studies need to examine larger and more samples of (T)LIS-patients in their living environment and everyday life.

The development of inexpensive hard- and software that can be easily adapted to multiple access modes and customized to the patients' individual needs should be a general goal. In the COGAIN ("communication by gaze interaction"; www. COGAIN.org) European Network of Excellence professionals and researchers collaborate toward developing advanced gaze based communication technologies in order to enhance applicability and user satisfaction of the devices and ensure quality control in patient care and research (194).

\section{Health Policy and Attitudes}

In addition to ALS and other motor neuron diseases, there is a high potential for HT-AAC to improve care for patients with other acquired neurological conditions that lead to impaired communication abilities, e.g., traumatic brain injury, brainstem impairment, severe chronic aphasia and apraxia of speech, primary progressive aphasia, and dementia (18). Depending on the particular type and extent of communication and/or motor and/or cognitive impairment that are caused by these conditions, different kinds of AAC-systems and functions can be assumed the most useful ones for the patient (e.g., typing vs. eyetracking communication devices; auto-correction function for aphasia patients). Based on an epidemiological approach, Creer et al. (195) estimated the prevalence of people who could benefit from AAC technologies in the UK at $0.5 \%$.

Enabling the individual's optimal communication capabilities should be the standard of care in order to maintain QoL and self-determination in the comprehensive and palliative care for all human beings including severely disabled 
patients. The German treatment guidelines for ALS (https: www.dgn.org/leitlinien/3012-ll-18-ll-amyotrophe-lateralsklerosemotoneuronerkrankungen) contain the general information that in case of dysarthria, dynamic AAC technologies with speech output and environment control should be procured. However, the guidelines do not offer detailed recommendations for assessment of communicative abilities for AAC evaluation and supply and do not refer to their value for patients' QoL. Moreover, they are not legally binding.

Furthermore, advance care planning in ALS should explicitly consider the possibility that patients' can reach a disease state in which communication is not possible at all. Advance care planning and power of attorney for caregivers, also including the termination of life-sustaining measures in ALS and other severe neurological disorders, is however a complex issue and thus beyond the focus of this review.

\section{CONCLUSIONS}

Usually, the term "palliative care" is not associated with high-technologies, probably because they are supposed to contribute to the dehumanization of medicine and the superiority of survival over QoL. However, HT-AAC devices are not conceived to prolong survival, but to enhance QoL and autonomy for the remaining lifetime which is a core component of palliative care. These HT-AAC devices thus should play an exceptional role in palliative care compared to many other high-tech devices normally used to prolong survival.

HT-AAC have a high potential for improving palliative care for people with ALS and other severe diseases that lead to impaired communication abilities. Several studies convincingly demonstrated that complex and caregiverindependent communication is enabled by HT-AAC, which is crucial for addressing psychological, spiritual, and essential issues in palliative care. Within the current knowledge, the use of HT-AAC respectively the optimization of patients' ability to communicate leads to improved QoL and better wellbeing and enables the maintenance of social roles and intellectual stimulation. Moreover, communication is essential for the prevention of patient autonomy concerning end-of-life care and decisions. The use of HT-AAC can therefore lead additionally to reduced caregiver-burden and strengthen family cohesion, which however needs further independent investigations, also concerning critical issues like barriers of acceptance of the devices.

The technology does also still possess unresolved pitfalls. These can be grouped by different aspects:

(i) Technically, limitations mainly arise from the infrared camera system with respect to distinct light conditions (mainly outside), wearing of glasses and body positioning.

(ii) Disease conditions such as cognitive, e.g. executive or social cognition deficits up to advanced dementia, language impairments including aphasia, but also TLIS or other eyegaze alterations obviously raise difficulties. (iii) Critical issues which can be solved more easily are such as barriers of acceptance amongst patients and caregivers, lack of awareness by both health care professionals and politicians/social system and the lack of clear and binding guidelines. The latter is also important to oblige HT-AAC providers to continually support the customer.

Healthcare professionals, technology providers as well as policy makers need a greater awareness of the possibilities but also of possible pitfalls of HT-AAC technologies. They are required to enable timely access to adequate, user-friendly and individually tailored equipment and provide ongoing training, customization and support (14), without letting quality of support suffer at the expense of cost effectiveness. This can be best achieved by individual evaluation of the patients' needs and concerns and by sufficient and continuous training in handling of the devices. It also includes the retraction of HT-AAC devices under certain circumstances, which might be severe dementia, development of significant gaze palsy or TLIS or also the patient's wish to return the device, which should optimally be properly assessed by means of the HT-AAC device.

On the basis of past and future research, detailed and binding guidelines that support patients' supply with AAC devices should be developed in order to ensure effective communication. Patients have to be enabled to make informed decisions for or against any communication support in order to allow the longest period of lifetime with the best possible QoL in accordance with their free will and their individual aims and wishes.

There is tremendous need for further research on the impact of HT-AAC, technical progress of the devices and for an increased awareness of upcoming opportunities and the importance of communication on wellbeing by professionals caring for severely disabled patients and by policy-makers. The consideration of HT-AAC interventions should be embedded as mandatory in multidisciplinary palliative care in order to enable autonomy by ensuring access to the best individually tailored communication strategies and their adjustment to changing needs of patients with ALS.

\section{AUTHOR CONTRIBUTIONS}

All authors listed have made a substantial, direct and intellectual contribution to the work, and approved it for publication.

\section{FUNDING}

The work was supported in part by a grant of the German ministry for education and research (BMBF, 16SV5843), the Roland Ernst Stiftung Sachsen and by the Innovationsausschuss des Gemeinsamen Bundesausschuss, Germany (FKZ 01VSF16026). 


\section{REFERENCES}

1. Andersen PM, Abrahams S, Borasio GD, de Carvalho M, Chio A, Van Damme P, et al. EFNS guidelines on the clinical management of amyotrophic lateral sclerosis (MALS) - revised report of an EFNS task force. Eur J Neurol. (2012) 19:360-75. doi: 10.1111/j.1468-1331.2011.03501.x

2. Spataro R, Bono V, Marchese S, La Bella V. Tracheostomy mechanical ventilation in patients with amyotrophic lateral sclerosis: clinical features and survival analysis. J Neurol Sci. (2012) 323:66-70. doi: 10.1016/j.jns.2012.08.011

3. Connolly S, Galvin M, Hardiman O. End-of-life management in patients with amyotrophic lateral sclerosis. Lancet Neurol. (2015) 14:435-42. doi: 10.1016/S1474-4422(14)70221-2

4. Martin S, Trevor-Jones E, Khan S, Shaw K, Marchment D, Kulka A, et al. The benefit of evolving multidisciplinary care in ALS: a diagnostic cohort survival comparison. Amyotroph Lateral Scler Frontotemporal Degener. (2017) 18:569-75. doi: 10.1080/21678421.2017.1349151

5. Van den Berg JP, Kalmijn S, Lindeman E, Veldink JH, de Visser M, Van der Graaff MM, et al. Multidisciplinary ALS care improves quality of life in patients with ALS. Neurology (2005) 65:1264-7. doi: 10.1212/01.wnl.0000180717.29273.12

6. Danel-Brunaud V, Touzet L, Chevalier L, Moreau C, Devos D, Vandolaeghe $\mathrm{S}$, et al. Ethical considerations and palliative care in patients with amyotrophic lateral sclerosis: a review. Rev Neurol. (2017) 173:300-7. doi: 10.1016/j.neurol.2017.03.032

7. Stavroulakis T, Baird WO, Baxter SK, Walsh T, Shaw PJ, McDermott CJ. The impact of gastrostomy in motor neurone disease: challenges and benefits from a patient and carer perspective. BMJ Support Palliat Care (2016) 6:52-9. doi: 10.1136/bmjspcare-2013-000609

8. Kaub-Wittemer D, Steinbüchel Nv, Wasner M, Laier-Groeneveld G, Borasio GD. Quality of life and psychosocial issues in ventilated patients with amyotrophic lateral sclerosis and their caregivers. J Pain Symptom Manage. (2003) 26:890-6. doi: 10.1016/S0885-3924(03)00323-3

9. Hogden A. Optimizing patient autonomy in amyotrophic lateral sclerosis: inclusive decision-making in multidisciplinary care. Neurodegener Dis Manag. (2014) 4:1-3. doi: 10.2217/nmt.13.71

10. Rabkin J, Ogino M, Goetz R, McElhiney M, Hupf J, Heitzman $\mathrm{D}$, et al. Japanese and American ALS patient preferences regarding TIV (tracheostomy with invasive ventilation): a cross-national survey. Amyotroph Lateral Scler Frontotemporal Degener. (2014) 15:185-91. doi: 10.3109/21678421.2014.896928

11. Tagami M, Kimura F, Nakajima H, Ishida S, Fujiwara S, Doi Y, et al. Tracheostomy and invasive ventilation in Japanese ALS patients: decisionmaking and survival analysis: 1990-2010. J Neurol Sci. (2014) 344:158-64. doi: 10.1016/j.jns.2014.06.047

12. Dreyer PS, Felding M, Klitnaes CS, Lorenzen CK. Withdrawal of invasive home mechanical ventilation in patients with advanced amyotrophic lateral sclerosis: ten years of Danish experience. J Palliat Med. (2012) 15:205-9. doi: 10.1089/jpm.2011.0133

13. Holmoy T, Aarestad S, Engstrand P, Ottesen S, Syse A, Forde R. Termination of mechanical ventilation in amyotrophic lateral sclerosis. Tidsskrift Nor Laegeforen (2009) 129:628-31. doi: 10.4045/tidsskr. 08.0006

14. Brownlee A, Palovcak M. The role of augmentative communication devices in the medical management of ALS. NeuroRehabilitation (2007) 22:445-50.

15. Oliver DJ, Borasio GD, Caraceni A, de Visser M, Grisold W, Lorenzl S, et al. A consensus review on the development of palliative care for patients with chronic and progressive neurological disease. Eur J Neurol. (2016) 23:30-8. doi: 10.1111/ene.12889

16. Cheng BHW, Chan KY, Chung YKJ, Choi CW, Chan $\mathrm{CH}$, Ching Cheng S, et al. Supportive \& palliative interventions in motor neuron disease: what we know from current literature? Ann Palliat Med. (2017). doi: 10.21037/apm.2017.10.01 [Epub ahead of print].

17. Hawthorn M. The importance of communication in sustaining hope at the end of life. Br J Nurs. (2015) 24:702-5. doi: 10.12968/bjon.2015.24. 13.702

18. Beukelman D, Fager S, Nordness A. Communication support for people with ALS. Neurol Res Int. (2011) 2011:714693. doi: 10.1155/2011/714693
19. Tomik B, Guiloff RJ. Dysarthria in amyotrophic lateral sclerosis: a review Amyotroph Lateral Scler. (2010) 11:4-15. doi: 10.3109/17482960802379004

20. Light J. "Communication is the essence of human life": reflections on communicative competence. Augment Altern Commun. (1997) 13:61-70. doi: 10.1080/07434619712331277848

21. McKelvey M, Evans DL, Kawai N, Beukelman D. Communication styles of persons with ALS as recounted by surviving partners. Augment Altern Commun. (2012) 28:232-42. doi: 10.3109/07434618.2012.737023

22. Felgoise SH, Zaccheo V, Duff J, Simmons Z. Verbal communication impacts quality of life in patients with amyotrophic lateral sclerosis. Amyotroph Lateral Scler Frontotemporal Degener. (2016) 17:179-83. doi: 10.3109/21678421.2015.1125499

23. Caroll-Thomas S. Communication changes and challenges in ALS/MND. J Speech Lang Pathol Audiol. (1995) 19:281-82.

24. Ball L, Nordness A, Fager S, Kersch K, Pattee G, Beukelmann D. Eye gaze access of AAC technology for persons with amyotrophic lateral sclerosis. $J$ Med Speech Lang Pathol. (2010) 18:11-23.

25. Caligari M, Godi M, Guglielmetti S, Franchignoni F, Nardone A. Eye tracking communication devices in amyotrophic lateral sclerosis; impact on disability and quality of life. Amyotroph Lateral Scler Frontotemporal Degener. (2013) 14:546-52. doi: 10.3109/21678421.2013. 803576

26. Ball L, Beukelmann D, Bilyeu D, Robertson D, Anderson P, Pattee G. Duration of AAC technology use by persons with ALS. J Med Speech Lang Pathol. (2007) 15:371-81.

27. Beukelman DR, Yorkston KM, Gorhoff SC, Mitsuda PM, Kenyon VT. Communication use by adults: a retrospective study. J Speech Hear Disord. (1981) 46:374-8. doi: 10.1044/jshd.4604.374

28. Gibbons C, Beneteau E. Functional performance using eye control and singles witch scanning by people with ALS. Perspect Augment Altern Commun. (2010) 19:64-9. doi: 10.1044/aac 19.3.64

29. Harris D, Goren M. The ERICA eye gaze system versus manual letter board to aid communication in ALS/MND. Br J Neurosci Nurs. (2009) 5:227-30. doi: 10.12968/bjnn.2009.5.5.42128

30. Blignaut P. Mapping the Pupil-Glint vector to gaze coordinates in a simple video-based eye tracker. J Eye Mov Res. (2013) 7:1-11. doi: 10.16910/jemr.7.1.4

31. Nguyen K, Wagner C, Koons D, Flickner M. Differences in the infrared bright pupil response of human eyes. In: Proceedings of the 2002 Symposium on Eye Tracking Research \& Applications. New Orleans, LA: ACM (2002). p. 133-8.

32. Ball LJ, Beukelman DR, Pattee GL. Acceptance of augmentative and alternative communication technology by persons with amyotrophic lateral sclerosis. Augment Altern Commun. (2004) 20:113-22. doi: 10.1080/0743461042000216596

33. Fager S, Hux K, Beukelman DR, Karantounis R. Augmentative and alternative communication use and acceptance by adults with traumatic brain injury. Augment Altern Commun. (2006) 22:37-47. doi: 10.1080/07434610500243990

34. Spataro R, Ciriacono M, Manno C, La Bella V. The eye-tracking computer device for communication in amyotrophic lateral sclerosis. Acta Neurol Scand. (2014) 130:40-5. doi: 10.1111/ane.12214

35. Fried-Oken M, Fox L, Rau MT, Tullman J, Baker G, Hindal M, et al. Purposes of AAC device use for persons with ALS as reported by caregivers. Augment Altern Commun. (2006) 22:209-21. doi: 10.1080/07434610600650276

36. Caron J, Light J. "My world has expanded even though I'm stuck at home": experiences of individuals with amyotrophic lateral sclerosis who use augmentative and alternative communication and social media. Am J Speech Lang Pathol. (2015) 24:680-95. doi: 10.1044/2015_AJSLP-15-0010

37. Linse K, Rüger W, Joos M, Schmitz-Peiffer H, Storch A, Hermann A. Usability of eyetracking computer systems and impact on psychological wellbeing in patients with advanced amyotrophic lateral sclerosis. Amyotroph Lateral Scler Frontotemporal Degener. (2018) 19:212-9. doi: $10.1080 / 21678421.2017 .1392576$

38. Calvo A, Chiò A, Castellina E, Corno F, Farinetti L, Ghiglione P, et al. Eye tracking impact on quality-of-life of ALS patients. In: Miesenberger K, Klaus J, Zagler W, Karshmer A, editors. Computers Helping People With Special 
Needs Proceedings of the 11th International Conference ICCHP 2008. Berlin, Heidelberg: Springer (2008). p. 70-7.

39. Pérez AIG, Dapueto JJ. Case report of a computer-assisted psychotherapy of a patient with ALS. Int J Psychiatry Med. (2014) 48:229-33. doi: 10.2190/PM.48.3.g

40. Hwang CS, Weng HH, Tsai CH, Chang HT. An eye-tracking assistive device improves quality of life for ALS patients and reduces caregivers' burden. $J$ Mot Behav. (2014) 46:233-8. doi: 10.1080/00222895.2014.891970

41. Londral A, Pinto A, Pinto S, Azevedo L, De Carvalho M. Quality of life in amyotrophic lateral sclerosis patients and caregivers: impact of assistive communication from early stages. Muscle Nerve (2015) 52:933-41. doi: $10.1002 /$ mus.24659

42. Corallo F, Bonanno L, Lo Buono V, De Salvo S, Rifici C, Pollicino P, et al. Augmentative and alternative communication effects on quality of life in patients with locked-in syndrome and their caregivers. J Stroke Cerebrovasc Dis. (2017) 26:1929-33. doi: 10.1016/j.jstrokecerebrovasdis.2017.06.026

43. McNaughton D, Light J, Groszyk L. "Don't give up": employment experiences of individuals with amyotrophic lateral sclerosis who use augmentative and alternative communication. Augment Altern Commun. (2001) 17:179-95. doi: 10.1080/aac.17.3.179.195

44. Linse K, Rüger W, Joos M, Schmitz-Peiffer H, Storch A, Hermann A. Eye-tracking-based assessment suggests preserved well-being in locked-in patients. Ann Neurol. (2017) 81:310-5. doi: 10.1002/ana.24871

45. Kübler A, Winter S, Ludolph AC, Hautzinger M, Birbaumer N. Severity of depressive symptoms and quality of life in patients with amyotrophic lateral sclerosis. Neurorehabil Neural Repair (2005) 19:182-93. doi: $10.1177 / 1545968305276583$

46. Chiò A, Gauthier A, Montuschi A, Calvo A, Di Vito N, Ghiglione P, et al. A cross sectional study on determinants of quality of life in ALS. J Neurol Neurosurg Psychiatry (2004) 75:1597-601. doi: 10.1136/jnnp.2003.033100

47. Neudert C, Wasner M, Borasio GD. Individual quality of life is not correlated with health-related quality of life or physical function in patients with amyotrophic lateral sclerosis. J Palliat Med. (2004) 7:551-7. doi: 10.1089/jpm.2004.7.551

48. McDonald ER, Wiedenfeld SA, Hillel A, Carpenter CL, Walter RA. Survival in amyotrophic lateral sclerosis: the role of psychological factors. Arch Neurol. (1994) 51:17-23. doi: 10.1001/archneur.1994.00540130027010

49. Johnston M, Earll L, Giles M, Mcclenahan R, Stevens D, Morrison V. Mood as a predictor of disability and survival in patients newly diagnosed with ALS/MND. Br J Health Psychol. (1999) 4:127-36. doi: 10.1348/135910799168524

50. Chiò A, Gauthier A, Calvo A, Ghiglione P, Mutani R. Caregiver burden and patients' perception of being a burden in ALS. Neurology (2005) 64:1780-2. doi: 10.1212/01.WNL.0000162034.06268.37

51. Gauthier A, Vignola A, Calvo A, Cavallo E, Moglia C, Sellitti L, et al. A longitudinal study on qality of life and depression in ALS patient-caregiver couples. Neurology (2007) 68:923-6. doi: 10.1212/01.wnl.0000257093.53430.a8

52. Lo Coco G, Lo Coco D, Cicero V, Oliveri A, Lo Verso G, Piccoli F, et al. Individual and health-related quality of life assessment in amyotrophic lateral sclerosis patients and their caregivers. J Neurol Sci. (2005) 238:11-7. doi: 10.1016/j.jns.2005.05.018

53. Creemers H, de Morée S, Veldink JH, Nollet F, van den Berg LH, Beelen A. Factors related to caregiver strain in ALS: a longitudinal study. J Neurol Neurosurg Psychiatry (2016) 87:775-81. doi: 10.1136/jnnp-2015-311651

54. Beeldman E, Raaphorst J, Klein Twennaar M, de Visser M, Schmand BA, de Haan RJ. The cognitive profile of ALS: a systematic review and meta-analysis update. J Neurol Neurosurg Psychiatry (2016) 87:611-9. doi: 10.1136/jnnp-2015-310734

55. Keller J, Gorges M, Horn HT, Aho-Ozhan HE, Pinkhardt EH, Uttner I, et al. Eye-tracking controlled cognitive function tests in patients with amyotrophic lateral sclerosis: a controlled proof-of-principle study. J Neurol. (2015) 262:1918-26. doi: 10.1007/s00415-015-7795-3

56. Poletti B, Carelli L, Solca F, Lafronza A, Pedroli E, Faini A, et al. An eyetracker controlled cognitive battery: overcoming verbal-motor limitations in ALS. J Neurol. (2017) 264:1136-45. doi: 10.1007/s00415-017-8506-z

57. Fager S, Beukelman D, Karantounis R, Jakobs T. Use of safe-laser access technology to increase head movement in persons with severe motor impairment: a series of case reports. Augment Altern Commun. (2006) 22:222-9. doi: 10.1080/07434610600650318

58. Trail M, Nelson ND, Van JN, Appel SH, Lai EC. A study comparing patients with amyotrophic lateral sclerosis and their caregivers on measures of quality of life, depression, and their attitudes toward treatment options. J Neurol Sci. (2003) 209:79-85. doi: 10.1016/S0022-510X(03)00003-0

59. Lulé D, Ehlich B, Lang D, Sorg S, Heimrath J, Kübler A, et al. Quality of life in fatal disease: the flawed judgement of the social environment. J Neurol. (2013) 260:2836-43. doi: 10.1007/s00415-013-7068-y

60. van Groenestijn AC, Kruitwagen-van Reenen ET, Visser-Meily JMA, van den Berg LH, Schröder CD. Associations between psychological factors and health-related quality of life and global quality of life in patients with ALS: a systematic review. Health Qual Life Outcomes (2016) 14:107. doi: 10.1186/s12955-016-0507-6

61. Lulé D, Hacker S, Ludolph A, Birbaumer N, Kubler A. Depression and quality of life in patients with amyotrophic lateral sclerosis. Dtsch Arztebl Int. (2008) 105:397-403. doi: 10.3238/arztebl.2008.0397

62. Ozanne AO, Graneheim UH, Strang S. Finding meaning despite anxiety over life and death in amyotrophic lateral sclerosis patients. J Clin Nurs. (2013) 22:2141-9. doi: 10.1111/jocn.12071

63. Raaphorst J, Visser Md, Linssen WHJP, Haan RJd, Schmand B. The cognitive profile of amyotrophic lateral sclerosis: a meta-analysis. Amyotroph Lateral Scler. (2010) 11:27-37. doi: 10.3109/17482960802645008

64. Phukan J, Elamin M, Bede P, Jordan N, Gallagher L, Byrne S, et al. The syndrome of cognitive impairment in amyotrophic lateral sclerosis: a population-based study. J Neurol Neurosurg Psychiatry (2011) 83:102-8. doi: 10.1136/jnnp-2011-300188

65. Stukovnik V, Zidar J, Podnar S, Repovs G. Amyotrophic lateral sclerosis patients show executive impairments on standard neuropsychological measures and an ecologically valid motor-free test of executive functions. J Clin Exp Neuropsychol. (2010) 32:1095-109. doi: 10.1080/13803391003749236

66. Fisher F, Philpott A, Andrews SC, Maule R, Douglas J. Characterizing social communication changes in amyotrophic lateral sclerosis. Int J Lang Commun Disord. (2017) 52:137-42. doi: 10.1111/1460-6984.12267

67. Bora E. Meta-analysis of social cognition in amyotrophic lateral sclerosis. Cortex (2017) 88:1-7. doi: 10.1016/j.cortex.2016.11.012

68. van der Hulst E-J, Bak TH, Abrahams S. Impaired affective and cognitive theory of mind and behavioural change in amyotrophic lateral sclerosis. J Neurol Neurosurg Psychiatry (2015) 86:1208-15. doi: 10.1136/jnnp-2014-309290

69. Lulé D, Nonnenmacher S, Sorg S, Heimrath J, Hautzinger M, Meyer T, et al. Live and let die: existential decision processes in a fatal disease. J Neurol. (2014) 261:518-25. doi: 10.1007/s00415-013-7229-z

70. Silverstein MD, Stocking CB, Antel JP, Beckwith J, Roos RP, Siegler M. Amyotrophic lateral sclerosis and life-sustaining therapy: patients' desires for information, participation in decision making, and life-sustaining therapy. Mayo Clin Proc. (1991) 66:906-13.

71. Ceriana P, Surbone S, Segagni D, Schreiber A, Carlucci A. Decision-making for tracheostomy in amyotrophic lateral sclerosis (ALS): a retrospective study. Amyotroph Lateral Scler Frontotemporal Degener. (2017) 18:492-7. doi: 10.1080/21678421.2017.1317812

72. Qutub K, Lacomis D, Albert SM, Feingold E. Life factors affecting depression and burden in amyotrophic lateral sclerosis caregivers. Amyotroph Lateral Scler Frontotemporal Degener. (2014) 15:292-7. doi: $10.3109 / 21678421.2014 .886699$

73. Larsson BJ, Fröjd C, Nordin K, Nygren I. Relatives of patients with amyotrophic lateral sclerosis: their experience of care and support. Palliat Support Care (2015) 13:1569-77. doi: 10.1017/S1478951515000188

74. Nakayama Y, Shimizu T, Mochizuki Y, Hayashi K, Matsuda C, Nagao $\mathrm{M}$, et al. Predictors of impaired communication in amyotrophic lateral sclerosis patients with tracheostomy-invasive ventilation. Amyotroph Lateral Scler Frontotemporal Degener. (2016) 17:38-46. doi: 10.3109/21678421.2015.1055276

75. Lasker JP, Bedrosian JL. Acceptance of AAC by adults with acquired disorders. In: Beukelman D, Yorkston K, Reichle J, editors. Augmentative Communication for Adults With Neurogenic and Neuromuscular Disabilities. Baltimore, MD: Paul H. Brooks (2000). p. 107-36. 
76. Sharma R, Hicks S, Berna CM, Kennard C, Talbot K, Turner MR. Oculomotor dysfunction in amyotrophic lateral sclerosis: a comprehensive review. Arch Neurol. (2011) 68:857-61. doi: 10.1001/archneurol.2011.130

77. Chang WD, Cha HS, Kim DY, Kim SH, Im CH. Development of an electrooculogram-based eye-computer interface for communication of individuals with amyotrophic lateral sclerosis. J Neuroeng Rehabil. (2017) 14:89. doi: 10.1186/s12984-017-0303-5

78. Lancioni GE, Simone IL, De Caro MF, Singh NN, O’Reilly MF, Sigafoos J, et al. Assisting persons with advanced amyotrophic lateral sclerosis in their leisure engagement and communication needs with a basic technology-aided program. NeuroRehabilitation (2015) 36:355-65. doi: 10.3233/NRE-151224

79. Smith E, Delargy M. Locked-in syndrome. BMJ (2005) 330:406-9. doi: 10.1136/bmj.330.7488.406

80. Hayashi H, Oppenheimer EA. ALS patients on TPPV: totally locked-in state, neurologic findings and ethical implications. Neurology (2003) 61:135-7. doi: 10.1212/01.WNL.0000069925.02052.1F

81. Murphy J. "I prefer contact this close": perceptions of AAC by people with motor neurone disease and their communication partners. Augment Altern Commun. (2009) 20:259-71. doi: 10.1080/07434610400005663

82. Käthner I, Kübler A, Halder S. Comparison of eye tracking, electrooculography and an auditory brain-computer interface for binary communication: a case study with a participant in the lockedin state. J Neuroeng Rehabil. (2015) 12:76. doi: 10.1186/s12984-0150071-z

83. Mathy P, Yorkston K, Gutman ML. AAC for individuals with amyotrophic lateral sclerosis. In: Beukelman D, Yorkston K, editors. Augmentative and Alternative Communication for Adults With Acquired Neurologic Disorders. Baltimore, MD: Paul H. Brooks (2000). p. 183-229.

84. Nordness AS, Ball LJ, Fager S, Beukelman DR, Pattee GL. Late AAC assessment for individuals with amyotrophic lateral sclerosis. J Med Speech Lang Pathol. (2010) 18:48-54.

85. Lakerveld J, Kotchoubey B, Kubler A. Cognitive function in patients with late stage amyotrophic lateral sclerosis. J Neurol Neurosurg Psychiatry (2008) 79:25-9. doi: 10.1136/jnnp.2007.116178

86. Kasper E, Zydatiss K, Schuster C, Machts J, Bittner D, Kaufmann J, et al. No change in executive performance in ALS patients: a longitudinal neuropsychological study. Neurodegener Dis. (2016) 16:184-91. doi: 10.1159/000440957

87. Mandler RN, Anderson FA Jr., Miller RG, Clawson L, Cudkowicz M, Bene MD. The ALS patient care database: insights into end-of-life care in ALS. Amyotroph Lateral Scler Other Motor Neuron Disord. (2001) 2:203-8. doi: 10.1080/14660820152882214

88. Donegan M, Morris JD, Corno F, Signorile I, Chió A, Pasian V, et al. Understanding users and their needs. Univers Access Inform Soc. (2009) 8:259-75. doi: 10.1007/s10209-009-0148-1

89. Funke A, Spittel S, Grehl T, Grosskreutz J, Kettemann D, Petri $S$, et al. Provision of assistive technology devices among people with ALS in Germany: a platform-case management approach. Amyotroph Lateral Scler Frontotemporal Degener. (2018) 19:342-50. doi: 10.1080/21678421.2018.1431786

90. Ball L, Schardt K, Beukelman D. Primary communication facilitators. Augment Commun News (2005) 17:6-7.

91. Fried-Oken M, Mooney A, Peters B. Supporting communication for patients with neurodegenerative disease. NeuroRehabilitation (2015) 37:6987. doi: $10.3233 / \mathrm{NRE}-151241$

92. Casey KS. Creating an assistive technology clinic: the experience of the Johns Hopkins AT clinic for patients with ALS. NeuroRehabilitation (2011) 28:281-93. doi: 10.3233/NRE-2011-0656

93. Rong P, Yunusova Y, Wang J, Zinman L, Pattee GL, Berry JD, et al. Predicting speech intelligibility decline in amyotrophic lateral sclerosis based on the deterioration of individual speech subsystems. PLoS ONE (2016) 11:e0154971. doi: 10.1371/journal.pone.0154971

94. Ball LJ, Beukelman DR, Pattee GL. Communication effectiveness of individuals with amyotrophic lateral sclerosis. J Commun Disord. (2004) 37:197-215. doi: 10.1016/j.jcomdis.2003.09.002

95. Renault S, Dhand A. Converse well-being of locked-in patients and caregivers. Ann Neurol. (2017) 82:490-1. doi: 10.1002/ana.25027
96. Aust E, Linse K, Rüger W, Joos M, Schmitz-Peiffer H, Storch A, et al. Reply to "Converse well-being of locked-in patients and caregivers". Ann Neurol. (2017) 82:491-3. doi: 10.1002/ana.25025

97. Mills T, Bunnell HT, Patel R. Towards personalized speech synthesis for augmentative and alternative communication. Augment Altern Commun. (2014) 30:226-36. doi: 10.3109/07434618.2014.924026

98. Lazarou I, Nikolopoulos S, Petrantonakis PC, Kompatsiaris I, Tsolaki M. EEG-based brain-computer interfaces for communication and rehabilitation of people with motor impairment: a novel approach of the 21st century. Front Hum Neurosci. (2018) 12:14. doi: 10.3389/fnhum.2018. 00014

99. Strong MJ, Abrahams S, Goldstein LH, Woolley S, McLaughlin P, Snowden J, et al. Amyotrophic lateral sclerosis-frontotemporal spectrum disorder (ALS-FTSD): revised diagnostic criteria. Amyotroph Lateral Scler Frontotemporal Degener. (2017) 18:153-74. doi: 10.1080/21678421.2016.1267768

100. Neumann M, Kwong LK, Sampathu DM, Trojanowski JQ, Lee VY. Tdp-43 proteinopathy in frontotemporal lobar degeneration and amyotrophic lateral sclerosis: protein misfolding diseases without amyloidosis. Arch Neurol. (2007) 64:1388-94. doi: 10.1001/archneur.64.10.1388

101. Montuschi A, Iazzolino B, Calvo A, Moglia C, Lopiano L, Restagno G, et al. Cognitive correlates in amyotrophic lateral sclerosis: a populationbased study in Italy. J Neurol Neurosurg Psychiatry. (2015) 86:168-73. doi: 10.1136/jnnp-2013-307223

102. Goldstein LH, Abrahams S. Changes in cognition and behaviour in amyotrophic lateral sclerosis: nature of impairment and implications for assessment. Lancet Neurol. (2013) 12:368-80. doi: 10.1016/S1474-4422(13)70026-7

103. Murphy J, Factor-Litvak P, Goetz R, Lomen-Hoerth C, Nagy PL, Hupf $\mathrm{J}$, et al. Cognitive-behavioral screening reveals prevalent impairment in a large multicenter ALS cohort. Neurology (2016) 86:813-20. doi: 10.1212/WNL.0000000000002305

104. Mioshi E, Caga J, Lillo P, Hsieh S, Ramsey E, Devenney E, et al. Neuropsychiatric changes precede classic motor symptoms in ALS and do not affect survival. Neurology (2014) 82:149-55. doi: 10.1212/WNL.0000000000000023

105. Ray J. Real-life challenges in using augmentative and alternative communication by persons with amyotrophic lateral sclerosis. Commun Disord Q. (2015) 36:187-92. doi: 10.1177/1525740114 545359

106. Montembeault M, Brambati SM, Joubert S, Boukadi M, Chapleau M, Laforce R Jr., et al. Naming unique entities in the semantic variant of primary progressive aphasia and Alzheimer's disease: towards a better understanding of the semantic impairment. Neuropsychologia (2017) 95:1120. doi: 10.1016/j.neuropsychologia.2016.12.009

107. Oh SJ, Eom B, Park C, Sung JE. Treatment efficacy of semantic feature analyses for persons with aphasia: evidence from meta-analyses. Commun Sci Disord. (2016) 21:310-23. doi: 10.12963/csd.16312

108. Phukan J, Pender NP, Hardiman O. Cognitive impairment in amyotrophic lateral sclerosis. Lancet Neurol. (2007) 6:994-1003. doi: 10.1016/S1474-4422(07)70265-X

109. Taylor LJ, Brown RG, Tsermentseli S, Al-Chalabi A, Shaw CE, Ellis CM, et al. Is language impairment more common than executive dysfunction in amyotrophic lateral sclerosis? J Neurol Neurosurg Psychiatry (2013) 84:494-8. doi: 10.1136/jnnp-2012-303526

110. Tsermentseli S, Leigh PN, Taylor LJ, Radunovic A, Catani M, Goldstein LH. Syntactic processing as a marker for cognitive impairment in amyotrophic lateral sclerosis. Amyotroph Lateral Scler Frontotemporal Degener. (2016) 17:69-76. doi: 10.3109/21678421.2015.1071397

111. Ash S, Olm C, McMillan CT, Boller A, Irwin DJ, McCluskey L, et al. Deficits in sentence expression in amyotrophic lateral sclerosis. Amyotroph Lateral Scler Frontotemporal Degener. (2015) 16:31-9. doi: 10.3109/21678421.2014.974617

112. Leslie FVC, Hsieh S, Caga J, Savage SA, Mioshi E, Hornberger $\mathrm{M}$, et al. Semantic deficits in amyotrophic lateral sclerosis. Amyotroph Lateral Scler Frontotemporal Degener. (2015) 16:46-53. doi: 10.3109/21678421.2014.987301 
113. Rakowicz WP, Hodges JR. Dementia and aphasia in motor neuron disease: an underrecognised association? J Neurol Neurosurg Psychiatry (1998) 65:881. doi: $10.1136 /$ jnnp.65.6.881

114. Abrahams S, Leigh P, Harvey A, Vythelingum NG, Grisé D, Goldstein L. Verbal fluency and executive dysfunction in amyotrophic lateral sclerosis (ALS). Neuropsychologia (2000) 38:734-47. doi: 10.1016/S0028-3932(99)00146-3

115. Shao Z, Janse E, Visser K, Meyer AS. What do verbal fluency tasks measure? Predictors of verbal fluency performance in older adults. Front Psychol. (2014) 5:772. doi: 10.3389/fpsyg.2014.00772

116. Funahashi S. Neuronal mechanisms of executive control by the prefrontal cortex. Neurosci Res. (2001) 39:147-65. doi: 10.1016/S0168-0102(00)00224-8

117. Diamond A. Executive functions. Annu Rev Psychol. (2013) 64:135-68. doi: 10.1146/annurev-psych-113011-143750

118. Espy KA. Using developmental, cognitive, and neuroscience approaches to understand executive control in young children. Dev Neuropsychol. (2004) 26:379-84. doi: 10.1207/s15326942dn2601_1

119. Kilani M, Micallef J, Soubrouillard C, Rey-Lardiller D, Dematteï C, Dib $\mathrm{M}$, et al. A longitudinal study of the evolution of cognitive function and affective state in patients with amyotrophic lateral sclerosis. Amyotroph Lateral Scler Other Motor Neuron Disord. (2004) 5:46-54. doi: 10.1080/14660820310017560

120. Wicks P, Abrahams S, Papps B, Al-Chalabi A, Shaw CE, Leigh PN, et al. SOD1 and cognitive dysfunction in familial amyotrophic lateral sclerosis. J Neurol. (2009) 256:234-41. doi: 10.1007/s00415-009-0078-0

121. Kasper E, Schuster C, Machts J, Bittner D, Vielhaber S, Benecke R, et al. Dysexecutive functioning in ALS patients and its clinical implications. Amyotroph Lateral Scler Frontotemporal Degener. (2015) 16:160-71. doi: 10.3109/21678421.2015.1026267

122. Pettit LD, Bastin ME, Smith C, Bak TH, Gillingwater TH, Abrahams S. Executive deficits, not processing speed relates to abnormalities in distinct prefrontal tracts in amyotrophic lateral sclerosis. Brain (2013) 136:3290-304. doi: 10.1093/brain/awt243

123. Volpato C, Piccione F, Silvoni S, Cavinato M, Palmeri R, Meneghello F, et al. Working memory in amyotrophic lateral sclerosis: auditory event-related potentials and neuropsychological evidence. J Clin Neurophysiol. (2010) 27:198-206. doi: 10.1097/WNP.0b013e3181e0aa14

124. Lillo P, Savage S, Mioshi E, Kiernan MC, Hodges JR. Amyotrophic lateral sclerosis and frontotemporal dementia: a behavioural and cognitive continuum. Amyotroph Lateral Scler. (2012) 13:102-9. doi: 10.3109/17482968.2011.639376

125. Flaherty-Craig C, Eslinger P, Stephens B, Simmons Z. A rapid screening battery to identify frontal dysfunction in patients with ALS. Neurology (2006) 67:2070. doi: 10.1212/01.wnl.0000247667.89251.43

126. Bak TH, Hodges JR. The effects of motor neurone disease on language: further evidence. Brain Lang. (2004) 89:354-61. doi: 10.1016/S0093-934X(03)00357-2

127. Chiò A, Calvo A, Ghiglione P, Mazzini L, Mutani R, Mora G, et al. Tracheostomy in amyotrophic lateral sclerosis: a 10-year populationbased study in Italy. J Neurol Neurosurg Psychiatry (2010) 81:1141-3. doi: 10.1136/jnnp.2009.175984

128. Henry JD, von Hippel W, Molenberghs P, Lee T, Sachdev PS. Clinical assessment of social cognitive function in neurological disorders. Nat Rev Neurol. (2016) 12:28-39. doi: 10.1038/nrneurol.2015.229

129. Lough S, Kipps CM, Treise C, Watson P, Blair JR, Hodges JR. Social reasoning, emotion and empathy in frontotemporal dementia. Neuropsychologia (2006) 44:950-8. doi: 10.1016/j.neuropsychologia.2005.08.009

130. Consonni M, Catricalà E, Dalla Bella E, Gessa VC, Lauria G, Cappa SF, Beyond the consensus criteria: multiple cognitive profiles in amyotrophic lateral sclerosis? Cortex (2016) 81:162-7. doi: 10.1016/j.cortex.2016.04.014

131. Burke T, Elamin M, Bede P, Pinto-Grau M, Lonergan K, Hardiman $\mathrm{O}$, et al. Discordant performance on the "Reading the Mind in the Eyes" test, based on disease onset in amyotrophic lateral sclerosis. Amyotroph Lateral Scler Frontotemporal Degener. (2016) 17:467-72. doi: $10.1080 / 21678421.2016 .1177088$

132. Sedda A. Disorders of emotional processing in amyotrophic lateral sclerosis. Curr Opin Neurol. (2014) 27:659-65. doi: 10.1097/WCO.0000000000000147
133. Andrews SC, Staios M, Howe J, Reardon K, Fisher F. Multimodal emotion processing deficits are present in amyotrophic lateral sclerosis. Neuropsychology (2017) 31:304-10. doi: 10.1037/neu0000323

134. Bora E, Köse S. Meta-analysis of theory of mind in anorexia nervosa and bulimia nervosa: a specific impairment of cognitive perspective taking in anorexia nervosa? Int J Eat Disord. (2016) 49:739-40. doi: 10.1002/eat. 22572

135. Sabbagh MA. Understanding orbitofrontal contributions to theory-ofmind reasoning: implications for autism. Brain Cogn. (2004) 55:209-19. doi: 10.1016/j.bandc.2003.04.002

136. Trojsi F, Di Nardo F, Santangelo G, Siciliano M, Femiano C, Passaniti C, et al. Resting state fMRI correlates of theory of mind impairment in amyotrophic lateral sclerosis. Cortex (2017) 97:1-16. doi: 10.1016/j.cortex.2017.09.016

137. Sterling LE, Jawaid A, Salamone AR, Murthy SB, Mosnik DM, McDowell E, et al. Association between dysarthria and cognitive impairment in ALS: a prospective study. Amyotroph Lateral Scler. (2010) 11:46-51. doi: 10.3109/17482960903207997

138. Goldstein LH, Adamson M, Jeffrey L, Down K, Barby T, Wilson C, et al. The psychological impact of MND on patients and carers. J Neurol Sci. (1998) 160:S114-21. doi: 10.1016/S0022-510X(98)00209-3

139. Gibbons ZC, Richardson A, Neary D, Snowden JS. Behaviour in amyotrophic lateral sclerosis. Amyotroph Lateral Scler. (2008) 9:67-74. doi: 10.1080/17482960701642437

140. Abdulla S, Machts J, Kaufmann J, Patrick K, Kollewe K, Dengler $\mathrm{R}$, et al. Hippocampal degeneration in patients with amyotrophic lateral sclerosis. Neurobiol Aging (2014) 35:2639-45. doi: 10.1016/j.neurobiolaging.2014.05.035

141. Raaphorst J, Tol MJ, Visser M, Kooi AJ, Majoie CB, Berg LH, et al. Prose memory impairment in amyotrophic lateral sclerosis patients is related to hippocampus. Eur J Neurol. (2015) 22:547-54. doi: 10.1111/ene.12615

142. Hervieu-Bègue M, Rouaud O, Graule Petot A, Catteau A, Giroud M. Semantic memory assessment in 15 patients with amyotrophic lateral sclerosis. Rev Neurol. (2016) 172:307-12. doi: 10.1016/j.neurol.2015.10.009

143. Lillo P, Mioshi E, Zoing MC, Kiernan MC, Hodges JR. How common are behavioural changes in amyotrophic lateral sclerosis? Amyotroph Lateral Scler. (2011) 12:45-51. doi: 10.3109/17482968.2010.520718

144. Mioshi E, Lillo P, Yew B, Hsieh S, Savage S, Hodges JR, et al. Cortical atrophy in ALS is critically associated with neuropsychiatric and cognitive changes. Neurology (2013) 80:1117-23. doi: 10.1212/WNL.0b013e31828869da

145. Woolley SC, Jonathan SK. Cognitive and behavioral impairment in amyotrophic lateral sclerosis. Phys Med Rehabil Clin N Am. (2008) 19:60717. doi: 10.1016/j.pmr.2008.04.002

146. Grossman AB, Woolley-Levine S, Bradley WG, Miller RG. Detecting neurobehavioral changes in amyotrophic lateral sclerosis. Amyotroph Lateral Scler. (2007) 8:56-61. doi: 10.1080/17482960601044106

147. Chiò A, Vignola A, Mastro E, Giudici AD, Iazzolino B, Calvo A, et al. Neurobehavioral symptoms in ALS are negatively related to caregivers' burden and quality of life. Eur J Neurol. (2010) 17:1298-303. doi: $10.1111 / j .1468-1331.2010 .03016 . x$

148. Wear HJ, Wedderburn CJ, Mioshi E, Williams-Gray CH, Mason SL, Barker RA, et al. The Cambridge behavioural inventory revised. Dement Neuropsychol. (2008) 2:102-7. doi: 10.1590/S1980-57642009DN20200005

149. Wei Q, Chen X, Cao B, Ou R, Zhao B, Wu Y, et al. Associations between neuropsychiatric symptoms and cognition in Chinese patients with amyotrophic lateral sclerosis. Amyotroph Lateral Scler Frontotemporal Degener. (2016) 17:358-65. doi: 10.3109/21678421.2016.1154574

150. Kurt A, Nijboer F, Matuz T, Kübler A. Depression and anxiety in individuals with amyotrophic lateral sclerosis. CNS Drugs (2007) 21:279-91. doi: 10.2165/00023210-200721040-00003

151. Braak H, Brettschneider J, Ludolph AC, Lee VM, Trojanowski JQ, Del Tredici K. Amyotrophic lateral sclerosis-a model of corticofugal axonal spread. Nat Rev Neurol. (2013) 9:708-14. doi: 10.1038/nrneurol.2013.221

152. Brettschneider J, Del Tredici K, Toledo JB, Robinson JL, Irwin DJ, Grossman $\mathrm{M}$, et al. Stages of pTDP-43 pathology in amyotrophic lateral sclerosis. Ann Neurol. (2013) 74:20-38. doi: 10.1002/ana.23937

153. Prudlo J, König J, Schuster C, Kasper E, Büttner A, Teipel S, et al. TDP-43 pathology and cognition in ALS. Neurology (2016) 87:1019. doi: 10.1212/WNL.0000000000003062 
154. Leeb R, Sagha H, Chavarriaga R, Millán JdR. A hybrid braincomputer interface based on the fusion of electroencephalographic and electromyographic activities. J Neural Eng. (2011) 8:025011. doi: 10.1088/1741-2560/8/2/025011

155. Kübler A, Furdea A, Halder S, Hammer EM, Nijboer F, Kotchoubey B. A brain-computer interface controlled auditory event-related potential (p300) spelling system for locked-in patients. Ann N Y Acad Sci. (2009) 1157:90-100. doi: 10.1111/j.1749-6632.2008.04122.x

156. Allison BZ, Wolpaw EW, Wolpaw JR. Brain-computer interface systems: progress and prospects. Expert Rev Med Devices (2007) 4:463-74. doi: 10.1586/17434440.4.4.463

157. Hochberg LR, Bacher D, Jarosiewicz B, Masse NY, Simeral JD, Vogel J, et al. Reach and grasp by people with tetraplegia using a neurally controlled robotic arm. Nature (2012) 485:372-5. doi: 10.1038/nature 11076

158. Wolpaw JR, Birbaumer N, Heetderks WJ, McFarland DJ, Peckham PH, Schalk G, et al. Brain-computer interface technology: a review of the first international meeting. IEEE Trans Rehabil Eng. (2000) 8:164-73. doi: 10.1109/TRE.2000.847807

159. Birbaumer N, Cohen LG. Brain-computer interfaces: communication and restoration of movement in paralysis. J Physiol. (2007) 579:621-36. doi: 10.1113/jphysiol.2006.125633

160. Birbaumer N, Gallegos-Ayala G, Wildgruber M, Silvoni S, Soekadar SR. Direct brain control and communication in paralysis. Brain Topogr. (2014) 27:4-11. doi: 10.1007/s10548-013-0282-1

161. Chaudhary U, Birbaumer N, Ramos-Murguialday A. Brain-computer interfaces for communication and rehabilitation. Nat Rev Neurol. (2016) 12:513-25. doi: 10.1038/nrneurol.2016.113

162. Chaudhary U, Xia B, Silvoni S, Cohen LG, Birbaumer N. Brain-computer interface-based communication in the completely locked-in state. PLoS Biol. (2017) 15:e1002593. doi: 10.1371/journal.pbio.1002593

163. Murguialday AR, Hill J, Bensch M, Martens S, Halder S, Nijboer F, et al. Transition from the locked in to the completely lockedin state: a physiological analysis. Clin Neurophysiol. (2011) 122:925-33. doi: 10.1016/j.clinph.2010.08.019

164. Guy V, Soriani MH, Bruno M, Papadopoulo T, Desnuelle C, Clerc M. Brain computer interface with the P300 speller: usability for disabled people with amyotrophic lateral sclerosis. Ann Phys Rehabil Med. (2018) 61:5-11. doi: 10.1016/j.rehab.2017.09.004

165. Ortiz-Rosario A, Adeli H. Brain-computer interface technologies: from signal to action. Rev Neurosci. (2013) 24:537-52. doi: 10.1515/revneuro-2013-0032

166. Jarosiewicz B, Sarma AA, Bacher D, Masse NY, Simeral JD, Sorice B, et al. Virtual typing by people with tetraplegia using a self-calibrating intracortical brain-computer interface. Sci Transl Med. (2015) 7:313ra179. doi: 10.1126/scitranslmed.aac7328

167. Spataro R, Chella A, Allison B, Giardina M, Sorbello R, Tramonte S, et al. Reaching and grasping a glass of water by locked-in ALS patients through a BCI-controlled humanoid robot. Front Hum Neurosci. (2017) 11:68. doi: 10.3389/fnhum.2017.00068

168. Burns A, Adeli H, Buford JA. Brain-computer interface after nervous system injury. Neuroscientist (2014) 20:639-51. doi: 10.1177/1073858414549015

169. Hinterberger T, Kübler A, Kaiser J, Neumann N, Birbaumer N. A braincomputer interface (BCI) for the locked-in: comparison of different EEG classifications for the thought translation device. Clin Neurophysiol. (2003) 114:416-25. doi: 10.1016/S1388-2457(02)00411-X

170. Neumann N, Birbaumer N. Predictors of successful self control during braincomputer communication. J Neurol Neurosurg Psychiatry (2003) 74:1117-21. doi: 10.1136/jnnp.74.8.1117

171. Neumann N, Kübler A, Kaiser J, Hinterberger T, Birbaumer N. Conscious perception of brain states: mental strategies for braincomputer communication. Neuropsychologia (2003) 41:1028-36. doi: 10.1016/S0028-3932(02)00298-1

172. Geronimo A, Simmons Z, Schiff SJ. Performance predictors of braincomputer interfaces in patients with amyotrophic lateral sclerosis. J Neural Eng. (2016) 13:026002. doi: 10.1088/1741-2560/13/2/026002

173. Nijboer F, Sellers EW, Mellinger J, Jordan MA, Matuz T, Furdea A, et al. A P300-based brain-computer interface for people with amyotrophic lateral sclerosis. Clin Neurophysiol. (2008) 119:1909-16. doi: 10.1016/j.clinph.2008.03.034

174. Ikegami S, Takano K, Kondo K, Saeki N, Kansaku K. A regionbased two-step P300-based brain-computer interface for patients with amyotrophic lateral sclerosis. Clin Neurophysiol. (2014) 125:2305-12. doi: 10.1016/j.clinph.2014.03.013

175. McCane LM, Heckman SM, McFarland DJ, Townsend G, Mak JN, Sellers EW, et al. P300-based brain-computer interface (BCI) eventrelated potentials (ERPs): people with amyotrophic lateral sclerosis (ALS) vs. age-matched controls. Clin Neurophysiol. (2015) 126:2124-31. doi: 10.1016/j.clinph.2015.01.013

176. McCane LM, Sellers EW, McFarland DJ, Mak JN, Carmack CS, Zeitlin D, et al. Brain-computer interface (BCI) evaluation in people with amyotrophic lateral sclerosis. Amyotroph Lateral Scler Frontotemporal Degener. (2014) 15:207-15. doi: 10.3109/21678421.2013.865750

177. Pires G, Nunes U, Castelo-Branco M. Statistical spatial filtering for a P300-based BCI: tests in able-bodied, and patients with cerebral palsy and amyotrophic lateral sclerosis. J Neurosci Methods (2011) 195:270-81. doi: 10.1016/j.jneumeth.2010.11.016

178. Pires G, Nunes U, Castelo-Branco M. Comparison of a row-column speller vs. a novel lateral single-character speller: assessment of BCI for severe motor disabled patients. Clin Neurophysiol. (2012) 123:1168-81. doi: 10.1016/j.clinph.2011.10.040

179. Pires G, Nunes U, Castelo-Branco M. Evaluation of brain-computer interfaces in accessing computer and other devices by people with severe motor impairments. Procedia Comput Sci. (2012) 14:283-92. doi: $10.1016 / j$.procs.2012.10.032

180. Sellers EW, Kubler A, Donchin E. Brain-computer interface research at the university of south Florida cognitive psychophysiology laboratory: the P300 speller. IEEE Trans Neural Syst Rehabil Eng. (2006) 14:221-4. doi: 10.1109/TNSRE.2006.875580

181. Silvoni S, Cavinato M, Volpato C, Ruf CA, Birbaumer N, Piccione F. Amyotrophic lateral sclerosis progression and stability of brain-computer interface communication. Amyotroph Lateral Scler Frontotemporal Degener. (2013) 14:390-6. doi: 10.3109/21678421.2013.770029

182. Kageyama Y, Hirata M, Yanagisawa T, Shimokawa T, Sawada J, Morris S, et al. Severely affected ALS patients have broad and high expectations for brainmachine interfaces. Amyotroph Lateral Scler Frontotemporal Degener. (2014) 15:513-9. doi: 10.3109/21678421.2014.951943

183. Marchetti M, Priftis K. Effectiveness of the P3-speller in brain-computer interfaces for amyotrophic lateral sclerosis patients: a systematic review and meta-analysis. Front Neuroeng. (2014) 7:12. doi: 10.3389/fneng.2014.00012

184. Huggins JE, Wren PA, Gruis KL. What would brain-computer interface users want? Opinions and priorities of potential users with amyotrophic lateral sclerosis. Amyotroph Lateral Scler. (2011) 12:318-24. doi: 10.3109/17482968.2011.572978

185. Kaufmann T, Holz EM, Kübler A. Comparison of tactile, auditory, and visual modality for brain-computer interface use: a case study with a patient in the locked-in state. Front Neurosci. (2013) 7:129. doi: 10.3389/fnins.2013.00129

186. Nam CS, Woo J, Bahn S. Severe motor disability affects functional cortical integration in the context of brain-computer interface (BCI) use. Ergonomics (2012) 55:581-91. doi: 10.1080/00140139.2011.647095

187. Holz EM, Botrel L, Kaufmann T, Kübler A. Long-term independent braincomputer interface home use improves quality of life of a patient in the locked-in state: a case study. Arch Phys Med Rehabil. (2015) 96:S16-26. doi: 10.1016/j.apmr.2014.03.035

188. Soukoureff RW. Quantifying Text Entry Performance. Dissertation, Toronto, CA: York University (2010).

189. Neuper C, Müller GR, Kübler A, Birbaumer N, Pfurtscheller G. Clinical application of an EEG-based brain-computer interface: a case study in a patient with severe motor impairment. Clin Neurophysiol. (2003) 114:399409. doi: 10.1016/S1388-2457(02)00387-5

190. Herold R, Vogel U, Richter B. OLED-on-CMOS based single chip microdisplay and image sensor device. In: 17th International Display Workshops (IDW). Fukuoka (2010). p. 339-40.

191. Hill NJ, Ricci E, Haider S, McCane LM, Heckman S, Wolpaw JR, et al. A practical, intuitive brain-computer interface for communicating 
"yes" or "no" by listening. J Neural Eng. (2014) 11:035003. doi: 10.1088/1741-2560/11/3/035003

192. Severens M, Waal MVd, Farquhar J, Desain P. Comparing tactile and visual gaze-independent brain-computer interfaces in patients with amyotrophic lateral sclerosis and healthy users. Clin Neurophysiol. (2014) 125:2297-304. doi: 10.1016/j.clinph.2014.03.005

193. Sellers EW, Vaughan TM, Wolpaw JR. A brain-computer interface for longterm independent home use. Amyotroph Lateral Scler. (2010) 11:449-55. doi: 10.3109/17482961003777470

194. Bates R, Donegan M, Istance HO, Hansen JP, Räihä K-J. Introducing COGAIN: communication by gaze interaction. Univers Access Inform Soc. (2007) 6:159-66. doi: 10.1007/s10209-007-0077-9

195. Creer S, Enderby P, Judge S, John A. Prevalence of people who could benefit from augmentative and alternative communication (AAC) in the
UK: determining the need. Int J Lang Commun Disord. (2016) 51:639-53. doi: 10.1111/1460-6984.12235

Conflict of Interest Statement: KL, EA, and AH have nothing to report. MJ's affiliation "Interactive Minds Dresden GmbH" is a provider of ETCS in the region of Dresden.

Copyright (c) 2018 Linse, Aust, Joos and Hermann. This is an open-access article distributed under the terms of the Creative Commons Attribution License (CC BY). The use, distribution or reproduction in other forums is permitted, provided the original author(s) and the copyright owner(s) are credited and that the original publication in this journal is cited, in accordance with accepted academic practice. No use, distribution or reproduction is permitted which does not comply with these terms. 